\title{
Gamma and Beta Oscillations Define a Sequence of Neurocognitive Modes Present in Odor Processing
}

\author{
-Donald E. Frederick, ${ }^{1,2}$ Austin Brown, ${ }^{3}$ Elizabeth Brim, ${ }^{3}$ Nisarg Mehta, ${ }^{2}$ Mark Vujovic, ${ }^{2}$ and ${ }^{-L e s l i e ~ M . ~ K a y ~}{ }^{1,2,3}$ \\ ${ }^{1}$ Department of Psychology, ${ }^{2}$ Institute for Mind and Biology, and ${ }^{3}$ The College, University of Chicago, Chicago, Illinois 60637
}

\begin{abstract}
Olfactory system beta $(15-35 \mathrm{~Hz})$ and gamma $(40-110 \mathrm{~Hz})$ oscillations of the local field potential in mammals have both been linked to odor learning and discrimination. Gamma oscillations represent the activity of a local network within the olfactory bulb, and beta oscillations represent engagement of a systemwide network. Here, we test whether beta and gamma oscillations represent different cognitive modes using the different demands of go/no-go and two-alternative choice tasks that previously were suggested to favor beta or gamma oscillations, respectively. We reconcile previous studies and show that both beta and gamma oscillations occur in both tasks, with gamma dominating the early odor sampling period (2-4 sniffs) and beta dominating later. The relative power and coherence of both oscillations depend separately on multiple factors within both tasks without categorical differences across tasks. While the early/gammaassociated period occurs in all trials, rats can perform above chance without the later/beta-associated period. Longer sampling, which includes beta oscillations, is associated with better performance. Gamma followed by beta oscillations therefore represents a sequence of cognitive and neural states during odor discrimination, which can be separately modified depending on the demands of a task and odor discrimination. Additionally, fast $(85 \mathrm{~Hz})$ and slow $(70 \mathrm{~Hz})$ olfactory bulb gamma oscillation sub-bands have been hypothesized to represent tufted and mitral cell networks, respectively (Manabe and Mori, 2013). We find that fast gamma favors the early and slow gamma the later (beta-dominated) odor-sampling period and that the relative contributions of these oscillations are consistent across tasks.
\end{abstract}

Key words: coherence; neural oscillation; olfactory bulb; piriform cortex

\section{Significance Statement}

Olfactory system gamma $(40-110 \mathrm{~Hz})$ and beta $(15-35 \mathrm{~Hz})$ oscillations of the local field potential indicate different neural firing statistics and functional circuits. We show that gamma and beta oscillations occur in stereotyped sequence during odor sampling in associative tasks, with local gamma dominating the first $250 \mathrm{~ms}$ of odor sniffing, followed by systemwide beta as behavioral responses are prepared. Oscillations and coupling strength between brain regions are modulated by task, odor, and learning, showing that task features can dramatically adjust the dynamics of a cortical sensory system, which changes state every $\sim 250 \mathrm{~ms}$. Understanding cortical circuits, even at the biophysical level, depends on careful use of multiple behavioral contexts and stimuli.

\section{Introduction}

Behavioral research has shown that almost any aspect of a task can affect subjects' strategies. What individuals and their brains do very

\footnotetext{
Received Feb. 19, 2016; revised June 4, 2016; accepted June 6, 2016

Author contributions: D.E.F. and L.M.K. designed research; D.E.F., A.B., E.B., N.M., and M.V. performed research; D.E.F. contributed unpublished reagents/analytic tools; D.E.F. analyzed data; D.E.F. and L.M.K. wrote the paper.

This work was supported by National Institute on Deafness and Other Communication Disorders Grant R01DC014367 to L.M.K. and Institute for Mind and Biology Seed Grant to LM.K. We thank Tasneem Amina, Çinar Doruk, Bethany Fixsen, Quincy John, Bianca Tamez-Buccino, Bolesław 0sinski, and Stephanie Tacopina for help with data collection and animal care; Daniel Rojas-Líbano for helpful comments on drafts; and Profs. Nicholas Hatsopoulos and Sara London for helpful comments on experiments. Finally, we thank Walter J. Freeman (1927-2016) for helpful comments and discussions on the data and results and dedicate this paper to his memory.

The authors declare no competing financial interests.

Correspondence should be addressed to Dr. Leslie M. Kay, Department of Psychology, University of Chicago, 5801 South Ellis Avenue, Chicago, IL 60637. E-mail: Ikay@uchicago.edu.

DOI:10.1523/JNEUROSCI.0569-16.2016

Copyright $\odot 2016$ the authors $\quad 0270-6474 / 16 / 367750-18 \$ 15.00 / 0$
}

well is respond flexibly to changing demands, and we assume that this flexibility is evident in the signals we use to describe brain function. Context-dependent neural activity changes have been described in many mammalian systems, particularly in the olfactory system, but we lack analysis of what contextual factors account for these changes and what might comprise an underlying stable network engaged in perceptual activity.

Olfactory system physiology is characterized by temporal and spatial neural dynamics (Freeman, 1975; Laurent et al., 1996; Schaefer and Margrie, 2007; Kay, 2011). Past research has shown meaning-dependent changes in the spatial evolution of EEG signals (Freeman and Schneider, 1982), mitral/tufted cell firing rates (Kay and Laurent, 1999; Doucette and Restrepo, 2008), and modulation of local field potential (LFP) gamma $(>40 \mathrm{~Hz})$ (Beshel et al., 2007) and beta oscillations (15-35 Hz) (Martin et al., 2004b, 2007). 
Olfactory bulb (OB) gamma and the analogous insect antennal lobe oscillation are functionally implicated in local discrimination of highly overlapping stimuli (Stopfer et al., 1997; Nusser et al., 2001; Beshel et al., 2007). However, mammalian beta oscillations may be better associated with odor learning than gamma (Martin et al., 2004b; Martin and Ravel, 2014) and represent the only consistently coherent band in this extended network, supporting the idea that beta oscillations are involved in joint dynamical states (Martin et al., 2007; Gourévitch et al., 2010; Kay and Beshel, 2010).

Olfactory decisions have a lower bound of a single sniff of 150 ms (Uchida and Mainen, 2003). The upper bound on processing has been argued to be as few as one or two sniffs (Zariwala et al., 2013) but could be longer depending upon the task, with indications in some studies that go/no-go (GNG) tasks may encourage longer sampling (Abraham et al., 2004). Even so, the initial 1-2 sniffs are modified depending on the odors to be detected (RojasLíbano and Kay, 2012) and may carry most of the objective sensory information (Wesson et al., 2008; Cury and Uchida, 2010).

We hypothesized two processing modes in olfaction: the first (fast) mode relying on gamma oscillations and a feedforward system resulting in fast discriminations; the second (slower) mode relying on beta oscillations, extended sampling, and larger involvement of higher-order brain regions. These modes are suggested by several studies. When centrifugal input is blocked, gamma oscillations become larger and more defined and beta oscillations are lost (Gray and Skinner, 1988; Neville and Haberly, 2003; Martin et al., 2006). Because experiments that showed differences in oscillation type also used different tasks, we further hypothesized that the processing mode depends on the task (Beshel et al., 2007; Martin et al., 2007; Kay et al., 2009) and other factors, such as odors and learning (Beshel et al., 2007; Lowry and Kay, 2007). Based on these earlier data, we predicted that twoalternative choice (TAC) tasks, with balanced action rewards and where speed may be preferred, engage a feed-forward gamma network (Friedrich, 2006; Kay et al., 2006). This would mean shorter sampling and larger modulation of gamma oscillations. For GNG tasks, with asymmetric reward and where deliberation may be preferred, we predicted a beta network that would recruit more of the olfactory system during longer sampling times.

To test these hypotheses, in Experiment 1 we trained two sets of rats to perform either a GNG or TAC task. To determine whether any differences present across groups were also present within individuals performing both tasks, in Experiment 2 we retrained three rats from Experiment 1 to perform both tasks. We found a stereotyped sequence of two states signified by gamma and beta oscillations. Both network modes are present in both tasks, and differences in degree depend on the task, phase of training, odors, and whether the rats know one or both tasks. Results suggest a sequence of dynamical states signified by different neural oscillations, early local gamma networks followed after 1-3 sniffs by systemwide beta oscillations, that may form the foundation for temporal integration and odor processing more generally.

\section{Materials and Methods}

Eight adult male Sprague Dawley rats were used (Harlan HSD; 400$450 \mathrm{~g}$ throughout the experiments). All rats were used for the first experiment. Three of the rats were also used in the second experiment. Rats were housed individually on a 14/10 h light/dark cycle (lights on at 0800 CST). All experiments were conducted during the light period. Before experiments, rats were dieted to $85 \%$ of their ad libitum weight and maintained at this level for the remainder of the experiments. All procedures were done under veterinary supervision and oversight of the Uni- versity of Chicago Institutional Animal Care and Use Committee in accordance with Association for Assessment and Accreditation of Laboratory Animal Care standards.

\section{Surgery}

Rats were initially sedated with a ketamine-xylazine mixture (subcutaneous injection; $35 \mathrm{mg} / \mathrm{kg}$ ketamine, $5 \mathrm{mg} / \mathrm{kg}$ xylazine, $0.75 \mathrm{mg} / \mathrm{kg}$ acepromazine). Rats were then given an initial dose of sodium pentobarbital (intraperitoneal; Nembutal $25 \mathrm{mg} / \mathrm{kg}$ ). Additional doses were given as needed. Rats were administered analgesic (subcutaneous; buprenorphine $0.05-0.1 \mathrm{mg} / \mathrm{kg}$ ) immediately after surgery, $12 \mathrm{~h}$ after surgery, and $24 \mathrm{~h}$ after surgery.

Rats were implanted with bipolar recording electrodes (100 $\mu \mathrm{m}$ stainless steel Formvar insulated, $\sim 1 \mathrm{~mm}$ tip separation, $100-350 \mathrm{k} \Omega$ impedance at $1 \mathrm{kHz}$ ) following our previously reported methods (Beshel et al., 2007; Martin et al., 2007; Rojas-Líbano and Kay, 2012) in the anterior/ dorsal OB ( $8.7 \mathrm{~mm}$ anterior to bregma, $1.5 \mathrm{~mm}$ lateral, $1.5 \mathrm{~mm}$ deep), posterior/ventral $\mathrm{OB}(8.3 \mathrm{~mm}$ anterior to bregma, $1.5 \mathrm{~mm}$ lateral and 4.3 $\mathrm{mm}$ deep), anterior pyriform cortex (aPC; $0.5 \mathrm{~mm}$ anterior to bregma, 3 $\mathrm{mm}$ lateral, $7.2 \mathrm{~mm}$ deep at a 15 degree angle from vertical), and posterior PC (pPC; $2.3 \mathrm{~mm}$ posterior to bregma, $3 \mathrm{~mm}$ lateral $8 \mathrm{~mm}$ deep at a 15 degree angle from vertical). Ground and reference electrodes were secured to head screws caudal to lambda. Electrodes were visualized to pierce the cortex, and signals were recorded as the electrode was lowered. A final location was selected if the signals on each electrode reversed themselves. If there was no reversal, the location with the largest amplitude was selected.

Each electrode was attached to a nine-pin connector (Ginder Scientific). Signals were acquired with a Neuralynx Cheetah32 system and a unity-gain headstage cable from NB Labs. Signals were amplified $4000 \times$, sampled at $2020.2 \mathrm{~Hz}$, and analog filters set at $1-325 \mathrm{~Hz}$. Because there was a substantial amount of movement artifact within the signals, all trials were checked by eye. Any trial that had artifact during the odor-sampling period or within $400 \mathrm{~ms}$ before nose-poke on was discarded. Recordings from the $\mathrm{pPC}$ are omitted from analysis due to poor signal quality from many of the subjects. Because we did not have good signals from both the $\mathrm{aOB}$ and $\mathrm{pOB}$ in all rats, we pooled the good trials from the $\mathrm{aOB}$ and $\mathrm{pOB}$ electrodes within each rat and labeled them as OB. The good trials from the aPC electrodes were pooled together within each rat and were labeled as aPC. Before analysis $60 \mathrm{~Hz}$ line noise was removed from the signals using the Chronux toolset (Bokil et al., 2010).

\section{Behavior}

Experiment 1: between subjects. Rats were initially trained in one of two behaviors (GNG or TAC) using our standard methods (Frederick et al., 2011). Training involves a progression through three phases. In Phase 1 , rats learn to nose-poke in the central odor port. In Phase 2, rats learn to nosepoke in a response port (located to the left of the central odor port) after first nose-poking in the odor port. In Phase 3, rats learn to either refrain from responding to a second odor (GNG behavior) or to respond into a right response port for a second odor (TAC behavior). Rats were reinforced with a sucrose pellet reward for correct go responses. A reward was one $45 \mathrm{mg}$ sucrose pellet (Bio-Serve Dustless Precision Pellets, \#F06233), delivered automatically after a correct response for a rewarded trial.

After training, the rats were implanted with electrodes (see Surgery). Two weeks after surgery, rats were retrained using the training odor set in the task that they had learned before surgery. After rats reached $>80 \%$ performance on the training odors, they were tested on the test odor sets. Rats were initially tested on odor sets S2-S4 (Table 1) with presentation order randomized. Then they were tested on the extreme odor set. This order was chosen because in a previous behavior study we found that, while rats could perform above chance on the extreme odor set, their performance was very low, and we wanted to test first in the normal condition due to the smaller numbers of animals for behavioral electrophysiology. Following completion of these odor sets, two new odor sets were devised and rats were tested on them (S5-S6) in order. Because of a technical error, two rats were run for more than the maximum of 10 days on an odor set. Results did not change whether or not these data were included. Therefore, we selected to retain these extra 
Table 1. Odor sets ${ }^{a}$

\begin{tabular}{|c|c|c|c|c|c|c|}
\hline Odor set & A & $\mathrm{VP}(\mathrm{kPa})$ & $\mathrm{VP}(\mathrm{mmHg})$ & B & $\mathrm{VP}(\mathrm{kPa})$ & $\mathrm{VP}(\mathrm{mmHg})$ \\
\hline Training & anisole & 0.524 & 3.93 & amyl acetate & 0.545 & 4.088 \\
\hline Extreme & $(+)$-limonene + trace & 0.206 & 1.545 & $(+)$-limonene + trace & 0.206 & 1.545 \\
\hline S2 & propyl proprionate & 1.859 & 13.943 & ethyl butyrate & 1.643 & 12.323 \\
\hline S3 & hexanal & 1.333 & 9.998 & ethyl benzene & 1.392 & 10.44 \\
\hline S4 & heptanone & 0.23 & 1.725 & octanone & 0.372 & 2.79 \\
\hline S5 & (+)-carvone/propyl proprionate & 0.816 & 6.12 & (+)-limonene/propyl proprionate & 0.767 & 5.753 \\
\hline S6 & MIX + citral & 0.032 & 0.24 & MIX + citronellal & 0.031 & 0.233 \\
\hline S8 & cineole & 0.185 & 1.388 & hexyl acetate & 0.219 & 1.643 \\
\hline
\end{tabular}

${ }^{a}$ Within each odor set, the odors are listed in order (odor A, B). MIX:0ctanol, decanol, hexanoic acid, + carvone, methyl furoate. Values retrieved from manufacturer websites orhttp://pubchem.ncbi.nlm.nih.gov/. Odors were purchased from Sigma-Aldrich (propyl proprionate, hexanal, hexyl acetate, decanol, hexanoic acid, methyl 2-fuorate), Fluka (anisole, citral), Fisher Scientific (ethylbenzene), and ACROS Organics (n-amyl acetate, 2-heptanone, 2-octanone, ethyl butyrate, d-limonene, cineole, octanol, carvone). Theoretical vapor pressure (VP) is given for each odor/mixture in $\mathrm{kPa}$ (kilo-Pascals) and mmHg.

days. Each session consisted of 150 trials. Rats were given one or more rest days between odor sets.

Experiment 2: within subject. After we had completed some of the planned data analysis at the end of Experiment 1, we began a second follow-up experiment on the remaining subset of Experiment 1 rats $(n=$ 3) to determine whether the results would hold when rats were challenged to do both tasks in the same day. The rats were trained on the behavior that they had not previously learned; two TAC rats were retrained to perform the GNG task, and one GNG rat was retrained to perform the TAC task. Once the rats had a solid command of both tasks, they were tested on the same day on both tasks. The order of the tasks was randomized within each day for each subject, and the rats were tested on three previously used odor sets (S2-S4) plus one new odor set (S8). Two rats had odor sets (S2-S4) interleaved such that they performed a different odor set each day for a total of $4 \mathrm{~d}$ per odor set. The particular sequence of odor sets across days was randomized. The third rat was tested in our usual block design on S2-S4 (as in Experiment 1) and then S8. Because of technical errors, this rat was tested on S2 for $6 \mathrm{~d}$ and S8 for $2 \mathrm{~d}$. As in Experiment 1, each session consisted of 150 trials, resulting in a total of 300 trials per day.

\section{Odor sets}

Odor sets were composed of two components (labeled A and B; Table 1). Components were either monomolecular (training odor set, extreme odor set, and odor sets 2-4 and 8) or mixtures (odor sets 5-6). For most of the monomolecular odor sets, the components were matched as closely as possible to avoid volatility differences that might drive differences in behavior or physiology (Lowry and Kay, 2007). For GNG, odor A was the go signal (i.e., rats were trained to respond to this stimulus with a nose-poke in the single response port on the left side) and odor B was the no-go signal (i.e., rats were trained to refrain from responding to this stimulus). For TAC, odor A was the go-left signal (i.e., rats were trained to make a response in a left response port to this stimulus) and odor B was the go-right signal (i.e., rats were trained to make a response in a right response port to this stimulus).

The extreme odor set was made using $(+)$-limonene and different trace airborne contaminants that were absorbed into the pure odorant. Test tubes that held the same odorant were contaminated by placing them in different experimental rooms, without a stopper, for at least $4 \mathrm{~h}$. The extreme odor set was inspired by a report that rats could discriminate between mineral oil made by different companies (Gamble and Smith, 2009).

\section{Statistical methods}

Statistical analysis was done using generalized least-square (GLS) methods to control for correlated data. Analysis was done in R using the gls and anova functions from the nlme package (Pinheiro and Bates, 2000; Pinheiro et al., 2016).

\section{Behavior analysis}

Session performance was calculated as the mean of the individual component performance: that is, (Performance(A) + Performance(B))/2). Session sampling duration was calculated as the median. GLS models were fit to determine whether task or odor set was a significant predictor of performance or sampling duration. We found significant effects and, therefore, have included performance and sampling duration as possible covariates in statistical models of the LFP. A full analysis of the behavior data is reported in a forthcoming paper.

\section{LFP analysis}

We did two different analyses with the LFP data. The first analysis looked at the mean spectral power level during two periods: the preodor period ( $-400 \mathrm{~ms}$ before nose-poke-on to nose-poke-on) and the odorsampling period (nose-poke-on to nose-poke-off plus $50 \mathrm{~ms}$ ). Spectral power was computed using MATLAB's native wavelet method (The MathWorks), cwt, with Morlet wavelets. Coherence was also computed using wavelet methods with Morlet wavelets in MATLAB using the wcoher method with time smoothing set to 50 points $(\sim 25 \mathrm{~ms})$ and scale smoothing set to 3 scales. We used the Fisher $Z$-transform ( $Z$-coherence $=\operatorname{arctanh}($ coherence $))$ to transform coherence, as we have in previous studies (Brillinger, 1981; Kay and Freeman, 1998; Kay and Beshel, 2010; Kay and Lazzara, 2010). This method spreads the usual $0-1$ coherence range to 0 to infinity, making the distribution statistically more tractable. Because the time windows are short, coherence values are generally overestimated. We therefore estimated the chance coherence levels and $95 \%$ CIs using resampling of the data. For each session, we selected 2000 random pairings of an $\mathrm{OB}$ and $\mathrm{aPC}$ trial (with replacement) and computed the coherence for the pairing of usually mismatched recordings. We then computed the mean and $95 \%$ CIs for each experiment using these values.

We first computed average values for each electrode as follows. For each trial within a session, we computed a time-frequency matrix $(X)$ and then divided the data into preodor $\left(X_{P r e}\right)$ and odor-sampling $\left(X_{O d o r}\right)$ periods. The odor-sampling period length varied based upon sampling duration. For each frequency band of interest $\left(f_{a}, f_{b}\right)$, we computed the preodor mean as follows:

$$
\bar{x}_{P r e}=\frac{1}{808} \sum_{t=1}^{808} \frac{1}{f_{b}-f_{a}} \sum_{f=f_{a}}^{f_{b}} X(t, f)
$$

and the odor-sampling period as follows:

$$
\bar{x}_{\text {Samp }}=\frac{1}{T-808} \sum_{t=809}^{T} \frac{1}{f_{b}-f_{a}} \sum_{f=f_{a}}^{f_{b}} X(t, f)
$$

where $t$ is time in data points $(1$ point $=1 / 2020.2 \mathrm{~s} ; 808$ points $=400 \mathrm{~ms})$ and $T$ is the total length of a trial (length of the odor-sampling period plus preodor period) in points. We then computed the odor session average values. To do this, we averaged the preodor and odor-sampling periods for each odor $(A, B)$. This resulted in four average values for each electrode for each frequency band of interest $\left(\bar{x}_{P r e, A}, \bar{x}_{\text {Pre, },}, \bar{x}_{\text {Oder, } A}, \bar{x}_{\text {Oder }, B}\right)$. We then averaged all the $\mathrm{OB}$ electrode values and all the aPC values to obtain a single set of averages for each brain region, which resulted in eight averaged values for each session for each frequency band of interest. These values were then used as the dependent variable (DV) values in statistical modeling. The general form of the model was as follows:

$$
\begin{aligned}
\mathrm{DV} \sim \text { task }+ \text { region }+ \text { odorSet }+ \text { component }+\operatorname{logVP} \\
\quad+\text { performance }+ \text { samplingDuration }+ \text { dayNumber }+\mathrm{CoV} .
\end{aligned}
$$


Task (GNG, TAC), region (OB, aPC), odor set (training, extreme, S2-S6, S8), and odor (A, B) were nominal variables. LogVP was the log theoretical vapor pressure of an odor, or mean if a mixture (for most odor sets, the $\operatorname{logVP}$ was matched for the two odors; Table 1). Performance was the performance for the odor (A, B) for the session. Sampling duration was the mean value for the odor (A, B) for the session. Day number was the testing day number within each odor set. $\mathrm{CoV}$ was an exponential covariance matrix meant to correct for correlated data terms. Figures and CIs produced from the lsmeans function, which produce least-square means (alternatively often called estimated marginal means), are estimated means from the fitted model. These means may not necessarily be the same as the arithmetic means of the underlying data. We present the least-square means and use them for interpretation because our argument stems from the model building. For the tables, we present the coefficients and SEs of the fixed effects for the fitted model. We place asterisks next to coefficient values that were significant based upon $t$ values from the GLS fit as seen in the summary command. We also place superscripts next to the factor name indicating which (if any) models were significant based upon the Wald $F$ test done using the anova function for each factor. We place a hashtag (\#) next to continuous factors (e.g., performance) that were significant based upon the Wald $F$ test but that were not significant as seen in the summary function based upon $t$ values. When the results differed between the coefficient $t$ value and Wald $F$ test, we built a new GLS model leaving out the covariate of interest. We then tested the two models against each other using the likelihood ratio tests with the anova function.

The second analysis, which we refer to as power or coherence trace models, focused on the temporal dynamics of the LFP power in each oscillation band. We performed this second analysis for two reasons. First, given that rats were able to select their own sampling durations, the first analysis could be confounded by temporal patterns of power across differing sampling durations. For example, beta oscillations could occur in a well-defined period of time (e.g., $400-800 \mathrm{~ms}$ ). If this were true, then rats that sampled significantly longer may have lower levels of beta power than rats that sampled just within the optimal period. Second, two mean level values could be arrived at by very different underlying dynamics. For example, a given level could be due to high levels of the underlying oscillation during one particular time period or to lower levels of the underlying oscillation across the entire period.

For the second analysis, instead of using mean values for the preodor and odor periods, we examined each time point between $-400 \mathrm{~ms}$ before nose-poke-on to $1000 \mathrm{~ms}$ after nose-poke-on (data used from each trial ended at the end of the sampling period $50 \mathrm{~ms}$ ). To do this, for each electrode we did the following. For each trial, we computed the timefrequency matrix $(X)$. Then, for each time point $(-400 \mathrm{~ms}$ to $1000 \mathrm{~ms})$ we found the average value for the frequency band of interest. We then divided the results into two sets based upon odor $(\mathrm{A}, \mathrm{B})$. Then, for each time point, we found the average within the two sets. Given that different trials had different sampling durations, we excluded trials for a given time point if that trial did not have data at that time point. For example, if there were 150 trials for odor A within a session, but only 130 of those trials had data at time point $t$, then only those 130 trials would be values used for averaging. This method produced two average values for each electrode within each session. We then averaged all the OB electrodes together and all the aPC electrodes together. Ultimately, this produced four averaged values within each session at each time point $\left(\bar{x}_{O B, A, t}, \bar{x}_{O B, B, t}, \bar{x}_{a P C, A, t}, \bar{x}_{a P C, B, t}\right)$ for a given frequency band. These values were then used as the DV value for the GLS models for each time point as follows:

$$
\begin{aligned}
\mathrm{DV}(\mathrm{t}) & \sim \text { task }+ \text { region }+ \text { odorSet }+ \text { component }+\log \mathrm{VP} \\
& + \text { performance }+ \text { samplingDuration }+ \text { dayNumber }+\mathrm{CoV} .
\end{aligned}
$$

For each time point, we also computed $95 \%$ CIs based upon the GLS models using lsmeans in $\mathrm{R}$, which are shown in Figures $4-7$. We also computed the $p$ values for task, brain region, odor set, and component for each time slice. Significant results $(p<0.05)$ are shown in Figures $3-6$ as black dots above the horizontal axis.
All figures were produced in MATLAB (R2015b). Figure adjustments (e.g., adding titles) were done in Adobe Photoshop CC (Adobe Systems, 2015).

\section{Results}

We hypothesized that rats engaged in GNG and TAC odor discrimination tasks would use beta and gamma networks differently, that the two frequency bands would represent different modes of processing driven by cognitive differences in task structure (e.g., behavioral responses, rewards). Experiment 1 was a between-subjects comparison, and Experiment 2 was a follow-up within-subjects experiment using a subset of the rats from Experiment 1 . In both experiments, we tested the effects of brain area and odor sets in addition to task. The general behavior protocol was the same for both experiments in which rats were trained to nose-poke into an odor-port, sniff an odor, and make a learned response based upon the odor. Rats were able to sniff the odor for as long as they wanted; we placed no minimum or maximum on how long the rats could sniff. To our knowledge, this paradigm is unique to our laboratory and allows us to explore behavior that may not be observed when sampling duration is capped at 1 or $2 \mathrm{~s}$ (Frederick et al., 2011; Rojas-Líbano and Kay, 2012).

In the first experiment, rats were trained and tested in either a GNG or TAC task ( $n=4$ /group) on many odor sets (Table 1 ). In the second experiment, three rats that had completed the first experiment were trained on the task that they had not previously learned and discriminated a subset of previously learned odor sets plus one new set. One GNG rat learned TAC, and two TAC rats learned GNG. In both experiments, LFP signals were recorded simultaneously from the $\mathrm{OB}$ and $\mathrm{PC}$, and we used these signals to identify what we call dynamical states, the oscillation mode used by a brain region or the entire system at a given time (gamma or beta oscillations). Statistical analyses of power and coherence were done by fitting GLS models. We present the results focusing on Experiment 1 and provide comparisons with Experiment 2 where the results differ.

\section{Behavioral comparisons}

Behavioral differences between tasks are the focus of a separate series of experiments in a forthcoming report. Here, we focus solely on those behavioral results necessary to interpret the electrophysiological results due to their inclusion in statistical models.

Behavior differed between the two experiments and between tasks based on the nature of the experiment. In Experiment 1, rats tested in GNG outperformed rats tested in TAC by $\sim 18 \%$, on average, based upon a weighted mean calculation $(\mathrm{GNG}=$ $[79.17,88.24 \%]$, TAC $=[61.34,68.86 \%], F_{(1,314)}=18.4168, p<$ 0.0001). In Experiment 2, where rats were trained and tested on both behaviors, performance did not differ significantly between tasks $(\mathrm{GNG}=[76.47,86.78 \%], \mathrm{TAC}=[81.22,91.20 \%]$, $F_{(1,102)}=0.1273$, n.s.).

Sampling duration differences between tasks also depended on the experiment. In Experiment 1, the sampling time difference between tasks was not significant $(\mathrm{GNG}=[439,525 \mathrm{~ms}], \mathrm{TAC}=$ $\left.[466,536 \mathrm{~ms}], F_{(1,323)}=2.0194, p=0.1563\right)$. In Experiment 2, rats sniffed $\sim 130 \mathrm{~ms}$ longer in the GNG than the TAC condition $\left(\mathrm{GNG}=[628,680 \mathrm{~ms}], \mathrm{TAC}=[496,547 \mathrm{~ms}], F_{(1,102)}=52.307\right.$, $p<0.0001)$. For $\sim 8 \mathrm{~Hz}$ sniff frequencies, which are widely reported for freely moving rats and mice during odor discrimination, this difference amounts to one additional sniff (Youngentob et al., 1987; Uchida and Mainen, 2003; Rajan et al., 2006; Kepecs et al., 2007; Rojas-Líbano and Kay, 2012). 


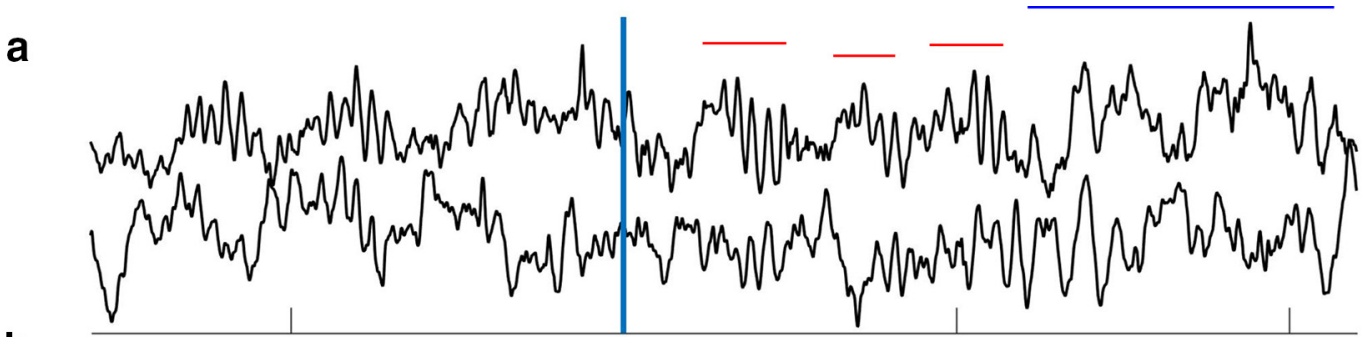

b
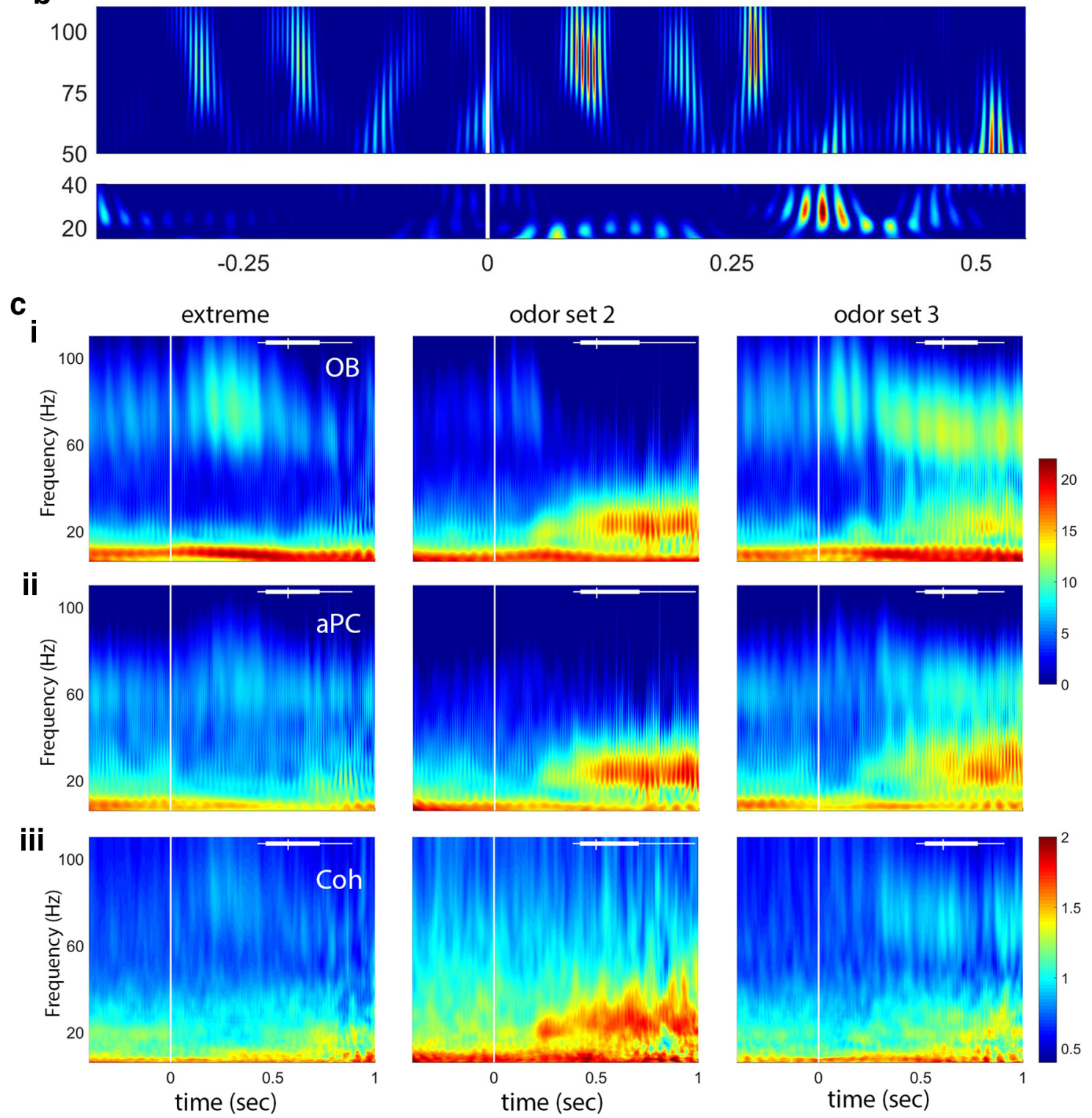

Figure 1. Data and frequency analysis. $\boldsymbol{a}$, Sample voltage traces showing gamma (red horizontal bars) and beta (blue horizontal bar) oscillations during a single trial. The vertical line at 0 indicates nose-poke-on, with the estimated arrival of the odor stimulus at $\sim 60 \mathrm{~ms}$ (Frederick et al., 2011). 0B is the top trace and aPC the bottom trace for the raw data. $\boldsymbol{b}$, Gamma (top) and beta (bottom) band wavelet plots showing frequency over time from the data in $\boldsymbol{a}$. Color represents power: red represents high. Note the sweep in frequency from higher to lower for the first two gamma bursts and the abrupt transition from gamma to beta just after $250 \mathrm{~ms}$. c, Sample wavelet time-frequency plots showing three session averages (columns represent three different odor sets). ci, OB power: note strong gamma during early odor sampling for the extreme odor set, lower-power gamma and strong beta for odor set 2 , and both gamma and beta power for odor set 3. cii, aPC power: note the similarity in beta power between OB and aPC. Gamma power in the aPC is much smaller than in the OB. ci, cii, The same color scale, which is in dimensionless units after normalization and log transform. ciii, Coherence between $0 B$ and aPC shows a decrease in strength during odor sampling in the lower frequency bands for the extreme odor set, and coherence overall is primarily limited to the beta band as reported previously (Kay and Beshel, 2010). Coherence is represented as Z-coherence (arctanh of coherence; see Materials and Methods). Vertical line at time 0 indicates nose-poke-on. White bar at top of each plot represents the distribution of end sampling times for each session. 


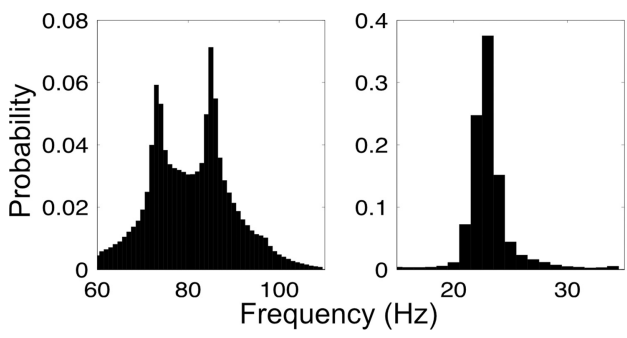

Figure 2. Wave-packet frequency distributions. Gamma (left) and beta (right) wavepacket mean frequency histograms. Distributions represent bursts collected from $0 \mathrm{~B}$ and $\mathrm{APC}$. Gamma occupies a broad band with twin peaks at $\sim 73 \mathrm{~Hz}$ and $\sim 85 \mathrm{~Hz}$ in both the $\mathrm{OB}$ and aPC. Beta occupies a narrow band centered at $\sim 23 \mathrm{~Hz}$.

Given these results, performance and sampling duration were added as covariates in the statistical models used below to control for the possibility that any differences in the LFP could be due to differences in performance and/or sampling durations and not to task or olfactory brain region.

\section{LFP comparisons}

During data collection and exploratory data analysis, we noted that LFP activity across tasks and odor sets was more similar than expected and followed a clear temporal pattern. Before nosepoke-on (which is the point at which odor would begin to be delivered; Fig. $1 a$, time $=0$ ) we observed occasional beta oscillations. At and following the initial nose poke, there were large gamma oscillations for 1-4 sniffs (example in Fig. $1 a, b$; we identify sniffs using the theta band of the OB LFP) (Rojas-Líbano et al., 2014). After those initial sniffs, the system transitioned to beta oscillations, the amplitude of which appeared to be odor set contingent. The three example sessions in Figure $1 c$ show the complex range of qualitative patterns that emerge during an odor session. Our highest overlap odor set, Extreme (+limonene/+ limonene with different trace contaminants in each odor sample; see Materials and Methods), shows large OB gamma in the early odor sampling period and little beta power in either brain region in the later part of odor sampling. Other odor discrimination pairs result in both gamma and beta oscillations (Fig. $1 c$; odor sets 2 and 3), and odor sets that are composed of odors with very low volatility (S6, data not shown, but see Figs. 4-7d, bottom) have low-power gamma and beta oscillations. These qualitative results suggest that there are multiple factors that determine the strength of gamma and beta oscillations.

To understand the frequency space in which the oscillation bursts, or wave packets (Freeman, 2003), occurred, we used an algorithm to extract time and band-limited oscillation bursts pooled across all sessions, experiments, and $\mathrm{OB}$ and aPC. Results showed that the mean frequency for gamma packets followed a bimodal distribution with peaks at 73 and $85 \mathrm{~Hz}$ (Fig. 2, left). Beta packets followed a unimodal distribution with a narrow peak at $23 \mathrm{~Hz}$ (Fig. 2, right). Given the bimodal distribution observed for gamma packets and recent hypotheses concerning the possibility of distinguishing mitral and tufted cell populations in LFP gamma oscillations (Manabe and Mori, 2013), we added an additional analysis to our planned analyses that focused on slow (62-80 Hz; presumed mitral cell) and fast $(80-110 \mathrm{~Hz}$; presumed tufted cell) gamma sub-bands. It should be noted that these gamma sub-bands do not correspond to gammal $(>60 \mathrm{~Hz})$ and gamma2 $(50-55 \mathrm{~Hz})$ in our earlier report (Kay, 2003) but are likely sub-bands of gamma1. While our division of gamma1 here is slightly different from that in Manabe and Mori (2013), it is common for frequencies within the gamma band to vary somewhat dependent on species, state of arousal, and other unknown factors (Bressler and Freeman, 1980; Kay et al., 2009).

First, we tested the session-averaged statistics within and between tasks on the preodor and odor periods. The odor period duration varied from trial to trial because it was defined as the period of time when the animal was in the odor-port plus $50 \mathrm{~ms}$ after the end of odor sampling. We defined the $400 \mathrm{~ms}$ period just before nose-poke-on as the preodor period. For the odor and preodor periods, the session statistics were computed as the average (power or coherence) over all the trials in a session, for each component. Statistical analysis was done by fitting GLS models to these period averaged values (see Materials and Methods).

While the above analysis gave us a mean picture of the differences between tasks, odors, and brain regions, it left out finer grained temporal dynamics. In other words, given any significant findings for the session-averaged statistics, were the differences driven by particular temporal patterns of the onset of beta and gamma oscillations? To analyze the data on a millisecond timescale, we computed GLS models at each time point (see Materials and Methods). We consider significant only those time points that cluster together, given the obvious issues with multiple comparisons. We refer to these analyses as "trace models," which represent analysis of sets of frequencies from the time-frequency wavelet based matrices.

Results are presented together grouped by frequency band, except for coherence, which is presented at the end of the results. Given the large number of statistical tests that were done, we have attempted clarity with brevity. Before analysis, we set a threshold of $\alpha=0.05$ as our decision boundary for significance. We report the GLS coefficients and SEs for analysis of power in tables (Tables 2-5. In the text, we report the Wald F test statistics when a factor was significant with the exception of the intercept, which we only report when pertinent to interpretation. Any factor in the analysis not mentioned in the text was not statistically significant. We present the results in each section in the order task, brain region, component odor $\mathrm{A}, \mathrm{B}$, and odor set, followed by additional significant effects within each frequency band, such as sampling duration and performance.

\section{Beta (15-35 Hz)}

We first analyzed session averages during the preodor and odor periods using the full periods. Across both experiments and both periods of analysis, we found several significant factors (for model fits, see Table 2; for 95\% CI for task and brain region, see Figure $3 a, b)$.

Task differences in beta power occurred in the preodor period but not in the odor period. In the preodor period in Experiment 1, rats performing the TAC task produced larger beta oscillations than rats performing the GNG task (Table 2; Fig. $\left.3 a ; F_{(1,1243)}=16.78, p<0.0001\right)$. The task difference was in the same direction in Experiment 2, but it was not significant $(p>0.05)$. This is in contrast to the odor periods in both Experiment 1 and Experiment 2 where there was no difference between tasks ( $p$ values $>0.05$ ).

Regional differences in beta power were small and not consistent across experiments. Beta power may be larger in the aPC than the OB during the odor period in Experiment 1 (Table 2; Fig. $3 b)$. Although the covariate was significant $(p=0.0484)$ within the GLS model, it was not significant when tested using Wald's $F$ test $\left(F_{(1,1243)}=3.70, p=0.0547\right)$. As a further test to determine whether brain region was significant, we built a new model leaving it out. We then tested this new model against the original 
Table 2. GLS model results for beta ${ }^{a}$

\begin{tabular}{|c|c|c|c|c|}
\hline & Odor period & & Preodor period & \\
\hline & E1 & E2 & E1 & E2 \\
\hline Intercept ${ }^{a, b, c, d}$ & $5.97(0.85)^{* * *}$ & $5.13(2.38)^{*}$ & $2.26(0.50)^{* * *}$ & $3.27(0.67)^{* * *}$ \\
\hline Task $^{c}$ & & & & \\
\hline GNG & Reference & & & \\
\hline TAC & $-0.14(0.26)$ & $-0.29(0.54)$ & $0.48(0.17)^{* *}$ & $0.07(0.16)$ \\
\hline Region & & & & \\
\hline$O B$ & Reference & & & \\
\hline $\mathrm{aPC}$ & $0.45(0.23)^{*}$ & $-0.68(0.53)$ & $0.30(0.16)$ & $0.47(0.16)^{* *}$ \\
\hline Odor set ${ }^{a, b}$ & & & & \\
\hline $\mathrm{T}$ & Reference & & & \\
\hline EX & $0.21(0.85)$ & - & $0.49(0.57)$ & - \\
\hline S2 & $1.60(0.92)$ & $3.7(1.94)$ & $0.69(0.63)$ & $-0.85(0.59)$ \\
\hline S3 & $0.10(0.84)$ & $-0.52(1.89)$ & $0.68(0.57)$ & $-1.11(0.57)$ \\
\hline S4 & $0.39(0.60)$ & $-1.23(1.55)$ & $-0.02(0.4)$ & $-0.85(0.45)$ \\
\hline S5 & $0.26(0.61)$ & - & $0.54(0.4)$ & - \\
\hline S6 & $1.99(2.08)$ & - & $0.79(1.43)$ & - \\
\hline S8 & - & $-2.38(1.91)$ & - & $-0.59(0.57)$ \\
\hline Odor ${ }^{b}$ & & & & \\
\hline A & Reference & & & \\
\hline B & $0.09(0.25)$ & $-1.18(0.57)^{*}$ & $0.07(0.17)$ & $-0.02(0.17)$ \\
\hline $\operatorname{logVP}($ power/kPa) & $0.96(0.70)$ & $-0.45(1.24)$ & $0.02(0.48)$ & $-0.11(0.39)$ \\
\hline Performance (power/\%) & $0.003(0.004)$ & $0.004(0.01)$ & $0.001(0.002)$ & $0.01(0.003)$ \\
\hline Sampling duration ${ }^{b, c, d, e}$ (power/ms) & $-0.004(0.001)^{* * *}$ & $0.003(0.001)^{*}$ & $-0.001(0.0003)^{* * *}$ & $0.001(0.0004)^{* *}$ \\
\hline $\operatorname{Day}^{e}($ power/d) & $-0.02(0.04)$ & $-0.18(0.16)$ & $0.04(0.02)$ & $-0.13(0.05)^{* *}$ \\
\hline
\end{tabular}

${ }^{a}$ Odor sets are identified in the coefficient column by name or $S+$ number (for odors, see Table 1). $\log V P$, Log of the average theoretical vapor pressure for the odor set; T-S8, odor sets (see Table 1).

${ }^{b}$ Odor Experiment 1 (Wald F test).

'Odor Experiment 2 (Wald F test).

${ }^{d}$ Preodor Experiment 1 (Wald F test).

ePreodor Experiment 2 (Wald F test).

${ }^{*} p=0.05 ;{ }^{* *} p=0.01 ;{ }^{* * *} p=0.001$ level; significant coefficient ( $t$ value); ${ }^{*}$ for a continuous factor, the Wald $\mathrm{F}$ test was significant, but the $t$ value for the coefficient was not significant.

Table 3. GLS model results for gamma power ${ }^{a}$

\begin{tabular}{|c|c|c|c|c|}
\hline & \multicolumn{2}{|l|}{ Odor period } & \multicolumn{2}{|l|}{ Preodor period } \\
\hline & $\mathrm{E} 1$ & E2 & $\mathrm{E} 1$ & E2 \\
\hline \multicolumn{5}{|l|}{ Task $^{d}$} \\
\hline GNG & Reference & & & \\
\hline TAC & $0.03(0.08)$ & $-0.05(0.15)$ & $0.15(0.06)^{* *}$ & $0.03(0.12)$ \\
\hline \multicolumn{5}{|l|}{ Region $b, c, d, e$} \\
\hline $\mathrm{OB}$ & Reference & & & \\
\hline $\mathrm{aPC}$ & $-0.83(0.07)^{* * *}$ & $-0.95(0.15)^{* * *}$ & $-0.58(0.05)^{* * *}$ & $-0.52(0.12)^{* * *}$ \\
\hline \multicolumn{5}{|l|}{ Odor set ${ }^{b, d}$} \\
\hline Training & Reference & & & \\
\hline Extreme & $0.22(0.25)$ & - & $0.08(0.19)$ & - \\
\hline S2 & $0.23(0.27)$ & $-0.25(0.52)$ & $0.19(0.20)$ & $-0.18(0.43)$ \\
\hline S3 & $0.36(0.25)$ & $-0.26(0.49)$ & $0.16(0.18)$ & $-0.24(0.41)$ \\
\hline S4 & $-0.21(0.18)$ & $-0.26(0.38)$ & $-0.14(0.13)$ & $-0.18(0.32)$ \\
\hline S5 & $-0.19(0.18)$ & - & $-0.08(0.13)$ & - \\
\hline S6 & $-0.19(0.62)$ & - & $-0.03(0.46)$ & - \\
\hline S8 & - & $-0.39(0.50)$ & - & $-0.32(0.41)$ \\
\hline \multicolumn{5}{|l|}{ Odor } \\
\hline Odor A & Reference & & & \\
\hline Odor B & $-0.02(0.07)$ & $0.09(0.16)$ & $0.03(0.05)$ & $0.01(0.13)$ \\
\hline $\log V P($ power/kPa) & $-0.04(0.21)$ & $-0.12(0.37)$ & $0.001(0.001)$ & $-0.00 .4(0.30)$ \\
\hline Performance ${ }^{d}$ (power/\%) & $0.001(0.001)$ & $0.004(0.002)$ & $0.001(0.001)^{\#}$ & $0.003(0.002)$ \\
\hline Samp duration ${ }^{b}$ (power/ms) & $-0.0004(0.0002)^{* *}$ & $-0.0003(0.0003)$ & $-0.0001(0.0001)$ & $-0.000(0.0002)$ \\
\hline Day (power/d) & $0.02(0.01)$ & $-0.02(0.04)$ & $0.01(0.01)$ & $-0.03(0.03)$ \\
\hline
\end{tabular}

For $a-e^{*}{ }^{* * *},{ }^{* * *}$, and \# definitions, see Table 2.

model (see Materials and Methods) and found that the model with brain region as a covariate was significantly better than the one without $(p=0.044)$. Therefore, it may be that there is a significant, but small, effect of brain region in Experiment 1 during the odor period. In Experiment 2, aPC power was larger only in the preodor period $\left(F_{(1,294)}=10.67, p=0.0012\right)$.
Components of odor sets were assigned to odors A and B (go and no-go in GNG, left and right response in TAC, respectively). Beta power did not vary significantly by odor (A, B) in Experiment 1 but varied significantly in Experiment 2 only during the odor period $\left(F_{(1,294)}=3.90, p=0.0493\right)$ with odor B producing less beta power than odor A (Table 2). Interaction terms were not 
Table 4. GLS model results for slow gamma power ${ }^{a}$

\begin{tabular}{|c|c|c|c|c|}
\hline & Odor period & & Preodor period & \\
\hline & E1 & E2 & E1 & E2 \\
\hline Intercept ${ }^{b, c, d, e}$ & $1.51(0.28)^{* * *}$ & $2.88(0.62)^{* * *}$ & $1.00(0.20)^{* * *}$ & $2.41(0.54)^{* * *}$ \\
\hline Task $^{d}$ & & & & \\
\hline GNG & Reference & & & \\
\hline TAC & $0.05(0.09)$ & $0.03(0.17)$ & $0.19(0.06)^{* *}$ & $0.18(0.14)$ \\
\hline Region ${ }^{b, c, d}$ & & & & \\
\hline $\mathrm{OB}$ & Reference & & & \\
\hline $\mathrm{aPC}$ & $-0.84(0.08)^{* * *}$ & $-0.79(0.16)^{* * *}$ & $-0.51(0.06)^{* * *}$ & $-0.16(0.14)$ \\
\hline Odor set ${ }^{b, d}$ & & & & \\
\hline Training & Reference & & & \\
\hline Extreme & $0.28(0.30)$ & - & $0.16(0.21)$ & - \\
\hline $\mathrm{S} 2$ & $0.32(0.33)$ & $-0.56(0.60)$ & $0.23(0.23)$ & $-0.44(0.50)$ \\
\hline S3 & $0.53(0.30)$ & $-0.53(0.57)$ & $0.20(0.21)$ & $-0.46(0.47)$ \\
\hline S4 & $-0.23(0.21)$ & $-0.65(0.44)$ & $-0.17(0.15)$ & $-0.48(0.38)$ \\
\hline S5 & $-0.19(0.21)$ & - & $-0.07(015)$ & - \\
\hline S6 & $-0.15(0.74)$ & - & $0.03(0.51)$ & - \\
\hline S8 & - & $-0.90(0.57)$ & - & $-0.66(0.48)$ \\
\hline Odor & & & & \\
\hline Odor A & Reference & & & \\
\hline Odor B & $-0.03(0.09)$ & $0.05(0.18)$ & $0.03(0.06)$ & $-0.05(0.15)$ \\
\hline logVP (power/kPa) & $-0.03(0.25)$ & $-0.19(0.41)$ & $0.03(0.17)$ & $-0.08(0.34)$ \\
\hline Performance $^{d}$ (power/\%) & $0.002(0.001)^{*}$ & $0.004(0.003)$ & $0.002(0.001)^{\#}$ & $0.002(0.003)$ \\
\hline Sampling duration ${ }^{b}$ (power/ms) & $-0.0004(0.0002)^{*}$ & $0.0001(0.0003)$ & $-0.0001(0.0001)$ & $0.0003(0.0003)$ \\
\hline $\operatorname{Day}^{b}$ (power/d) & $0.02(0.01)^{*}$ & $-0.05(0.04)$ & $0.01(0.01)$ & $-0.06(0.04)$ \\
\hline
\end{tabular}

For $a-e^{*}{ }^{*},{ }^{* *},{ }^{* * *}$, and \# definitions, see Table 2.

Table 5. GLS results for fast gamma power ${ }^{a}$

\begin{tabular}{|c|c|c|c|c|}
\hline & \multicolumn{2}{|l|}{ Odor period } & \multicolumn{2}{|l|}{ Preodor period } \\
\hline & E1 & E2 & E1 & E2 \\
\hline Intercept ${ }^{b, c, d, e}$ & $1.21(0.21)^{* * *}$ & $1.80(0.49)^{* * *}$ & $0.89(0.16)^{* * *}$ & $1.40(0.43)^{* *}$ \\
\hline \multicolumn{5}{|l|}{ Task $^{d}$} \\
\hline GNG & Reference & & & \\
\hline TAC & $0.02(0.07)$ & $-0.13(0.14)$ & $0.11(0.05)^{*}$ & $-0.13(0.12)$ \\
\hline \multicolumn{5}{|l|}{ Region $b, c, d, e$} \\
\hline $\mathrm{OB}$ & Reference & & & \\
\hline $\mathrm{aPC}$ & $-0.85(0.06)^{* * *}$ & $-1.17(0.14)^{* * *}$ & $-0.68(0.05)^{* * *}$ & $-0.93(0.12)^{* * *}$ \\
\hline \multicolumn{5}{|l|}{ Odor set ${ }^{b, d}$} \\
\hline Training & Reference & & & \\
\hline Extreme & $0.16(0.23)$ & - & $-0.002(0.18)$ & - \\
\hline $\mathrm{S} 2$ & $0.14(0.25)$ & $0.07(0.51)$ & $0.15(0.20)$ & $0.13(0.42)$ \\
\hline S3 & $0.18(0.23)$ & $0.03(0.48)$ & $0.11(0.18)$ & $0.03(0.40)$ \\
\hline S4 & $-0.19(0.16)$ & $0.15(0.37)$ & $-0.11(0.13)$ & $0.18(0.31)$ \\
\hline S5 & $-0.20(0.16)$ & - & $-0.10(0.13)$ & - \\
\hline S6 & $-0.23(0.57)$ & - & $-0.09(0.45)$ & - \\
\hline S8 & - & $0.16(0.49)$ & - & $0.09(0.40)$ \\
\hline \multicolumn{5}{|l|}{ Odor } \\
\hline Odor A & Reference & & & \\
\hline Odor B & $-0.02(0.07)$ & $0.13(0.16)$ & $0.03(0.05)$ & $0.07(0.13)$ \\
\hline $\log V P($ power/kPa) & $-0.05(0.19)$ & $-0.06(0.37)$ & $0.004(0.15)$ & $-0.0001(0.29)$ \\
\hline Performance ${ }^{d, e}$ (power/\%) & $0.001(0.001)$ & $0.005(0.002)$ & $0.001(0.001)^{\#}$ & $0.005(0.002)^{*}$ \\
\hline Sampling duration ${ }^{b, c}$ (power/ms) & $-0.0003(0.0001)^{*}$ & $-0.001(0.0002)^{* *}$ & $-0.0001(0.0001)$ & $-0.0002(0.0002)$ \\
\hline Day (power/d) & $0.01(0.01)$ & $0.01(0.03)$ & $0.01(0.01)$ & $0.0004(0.03)$ \\
\hline
\end{tabular}

For $a-e^{*},{ }^{* * *},{ }^{* * *}$, and \# definitions, see Table 2.

significant, so it is unlikely that the response asymmetry in GNG drove any differences.

Odor set was the major determinant of differences in beta power. In both experiments, odor set was a significant factor during the odor period (Table 2; Experiment 1: $F_{(6,1243)}=16.80$, $p<0.001$; Experiment 2: $\left.F_{(4,294)}=15.59, p<0.001\right)$. S2 produced the largest beta power. Post hoc multiple comparisons (using Bonferroni adjustments; Experiment 2: $\alpha=0.0024$, E3: $\alpha=$ 0.005 ) suggest that in both experiments $S 2$ beta was significantly larger than S3 beta (Experiment 1: $p=0.0004$; Experiment 2: $p<$ $0.0001)$.
Beta power was associated with sampling duration in both experiments during both the preodor and odor periods but in opposite directions (Table 2; Wald $\mathrm{F}$ test was significant for all but Experiment 2 odor period. Experiment 1 (odor): $F_{(1,1243)}=$ 37.37, $p<0.001$; Experiment 1 (preodor): $F_{(1,1243)}=23.86, p<$ 0.0001 ; Experiment 2 (odor): $F_{(1,294)}=3.83, p=0.0512$; Experiment 2 (preodor): $\left.F_{(1,294)}=8.76, p=0.0033\right)$. Associations with preodor beta mean that the amount of beta power before the sampling period can predict the duration of the subsequent sampling period. Associations with odor period beta mean that larger or smaller beta power is associated with longer sampling dura- 

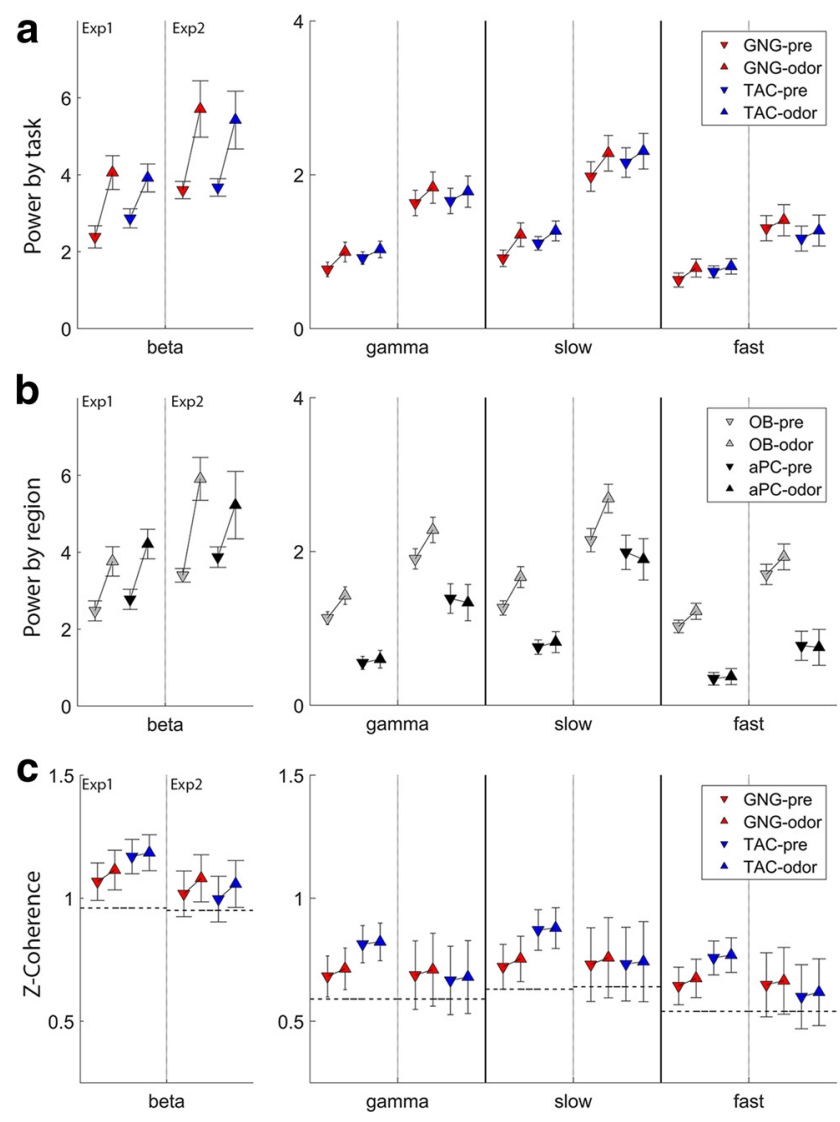

Figure 3. Summary of session statistics. Session statistics are computed on the entire odor or preodor period using GLS models across all factors listed in Tables $2-5$. Results are displayed for preodor and odor periods for each band and experiment. Within each band, the left 2 pairs of markers are for Experiment 1, and the right for Experiment 2 for comparison. The scale for beta power is larger than for the gamma bands. $\boldsymbol{a}$, Power comparisons by task for beta, gamma, slow gamma, and fast gamma. $\boldsymbol{b}$, Power comparisons by brain region (OB and aPC). C, OB-aPC $z$-coherence (arctanh of coherence) values. Dashed horizontal lines indicate the values from shuffled trials for estimate of the random values.

tions. In Experiment 1, during both the preodor and odor periods, sampling duration was negatively correlated with increased beta power such that each $100 \mathrm{~ms}$ of odor sampling was predicted by a decrease of 0.1 unit of preodor beta and associated with a decrease of 0.4 unit of beta in the odor period. In Experiment 2, increased sampling duration was positively correlated with beta power such that each $100 \mathrm{~ms}$ of sniffing was predicted by an increase of 0.1 unit of beta power during the preodor period and associated with an increase of 0.3 unit of beta power during the odor period.

Previous studies on beta power have shown that beta increases with learning (Martin et al., 2004b, 2007). In Experiment 1, each rat was tested on each odor set until the performance criterion of $80 \%$ or $10 \mathrm{~d}$, so we expected to replicate the increase of beta over days as rats learned to discriminate each of the odor sets. Day was a significant factor in beta power only during the preodor period in Experiment $2\left(F_{(1,294)}=7.51, p=0.0065\right)$; with each additional day, within an odor set, preodor beta power decreased by 0.13 unit. In Experiment 1, beta power during odor sampling did not change significantly over days, in contrast to previous studies; and in Experiment 2, beta power changed only in the preodor period and opposite the expected direction.

Summarizing the session beta band statistics: When rats performed only one task (Experiment 1), beta power was stronger in
aPC than $\mathrm{OB}$ and stronger in TAC than GNG before the odor started; during odor sampling, there were no differences in task or brain region. In Experiment 1, beta power scaled with odor set, with S2 producing the largest beta oscillations, the Extreme odor set, and S3 the smallest beta, and all test odor sets larger than the training odor set, matching our previous results (Martin et al., 2007). We did not replicate previously observed increases in beta power with learning across days (Martin et al., 2004b, 2007). Sampling duration during the odor period in Experiment 1 decreased in proportion to preodor and odor period beta power increases.

There were some differences when rats performed both tasks in Experiment 2. Beta power did not vary significantly across tasks but was still larger in the aPC than the $\mathrm{OB}$ in the preodor period. Beta power in Experiment 2 was significantly affected by the odor sets, similar to Experiment 1, but the training odor set produced large beta in Experiment 2, in contrast to Experiment 1. In Experiment 1, the training odor set was the odor set on which the rats first learned the task. In Experiment 2, this same odor set was used during retraining to a new task, but neither the task nor the odor set was entirely new. Sampling duration was related to beta power in the opposite direction in Experiment 2 relative to Experiment 1. Increases in odor sampling time were associated with increases in beta power in preodor and odor periods.

The session statistics give us tractable statistical samples with low numbers of comparisons, but examination of the raw data shows that beta oscillations endure for only a portion of the odor sampling period or preodor period (Figs. 1, 4). Therefore, we analyzed the data with an eye for temporal dynamics using the trace analysis as described in Materials and Methods. Beta band trace models revealed additional information on temporal structure within a sampling bout. In both experiments, beta power during odor sampling is not elevated until 200-250 ms after the nose-poke, or after at least 1-2 full sniffs of the odor stimulus (estimated odor delay is $60 \mathrm{~ms}$; Fig. $4 a$ ). In Experiment 1, there are extensive periods of significant task differences in beta power in the preodor period, where TAC has stronger prestimulus beta than GNG (Fig. 4ai), matching the session statistics. Also in Experiment 1, aPC shows stronger beta than $\mathrm{OB}$ for extended preodor and odor periods, but only in the preodor and early odor periods in Experiment 2 (Fig. 4b); these results vary somewhat from those derived from session statistics above, which do not take account of differences in portions of a sampling period. In Experiment 2, the odor A beta power increase began earlier than odor B, contributing to the significant odor effect in session statistics (Fig. 4cii, Table 2). The most robust modulation of beta power was due to the odor set, where beta power varied not only in overall power but also in temporal dynamics (Fig. 4d).

\section{Gamma $(62-110 \mathrm{~Hz})$}

Recently, it has been proposed that differential activity of mitral and tufted cells may be inferred by activity in discrete gamma bands, where higher frequency gamma oscillations may signify tufted cell firing and lower frequency may signify mitral cell firing (Manabe and Mori, 2013). Given this hypothesis and the pronounced bimodal distribution of mean gamma frequencies for individual wave-packets (Fig. 2), in addition to the broadband gamma analysis, we divided the gamma band into slow (62-80 $\mathrm{Hz})$ and fast $(80-110 \mathrm{~Hz})$ bands. Analysis followed the same pattern as that outlined for beta oscillations, focusing first on the 

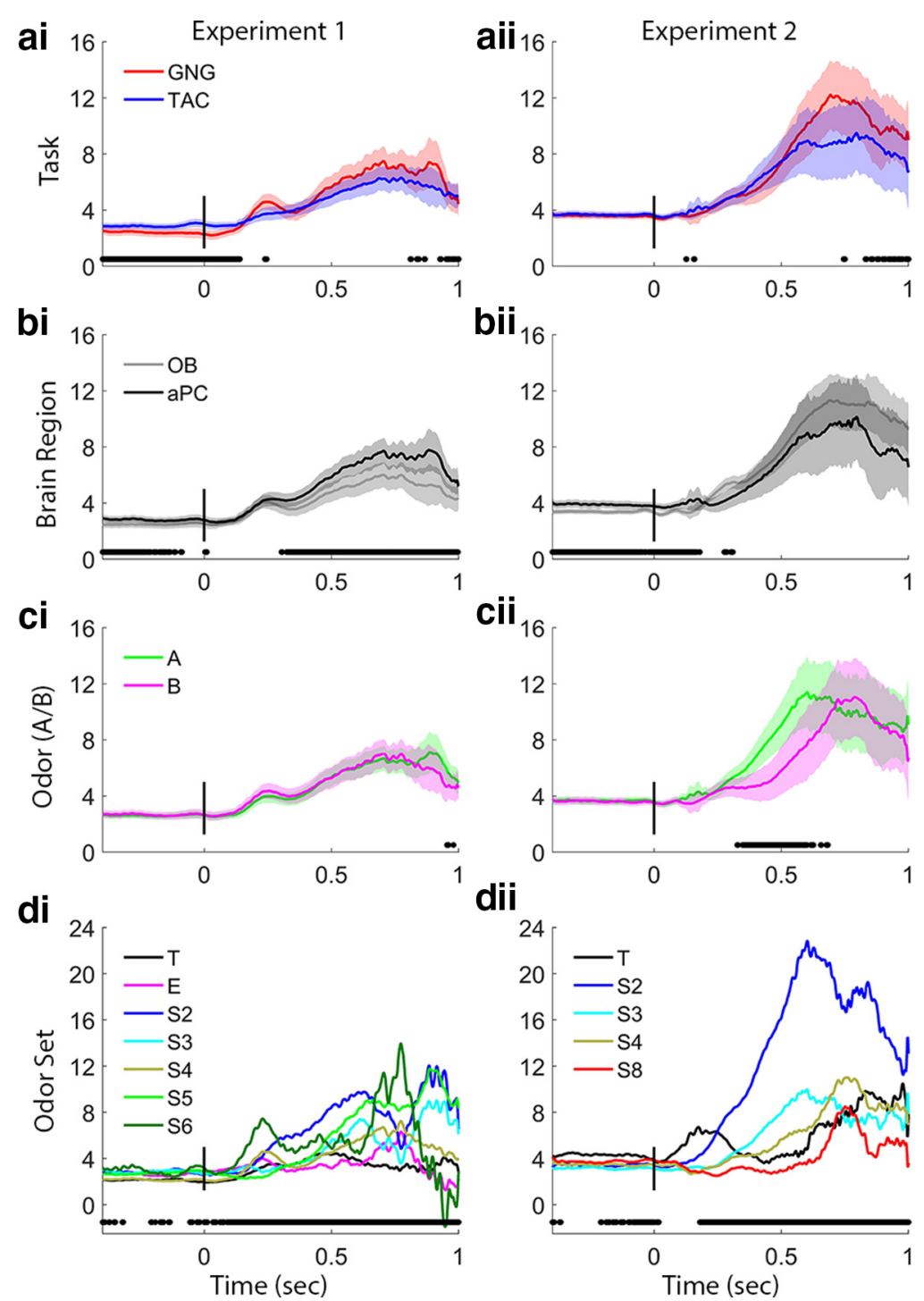

bii
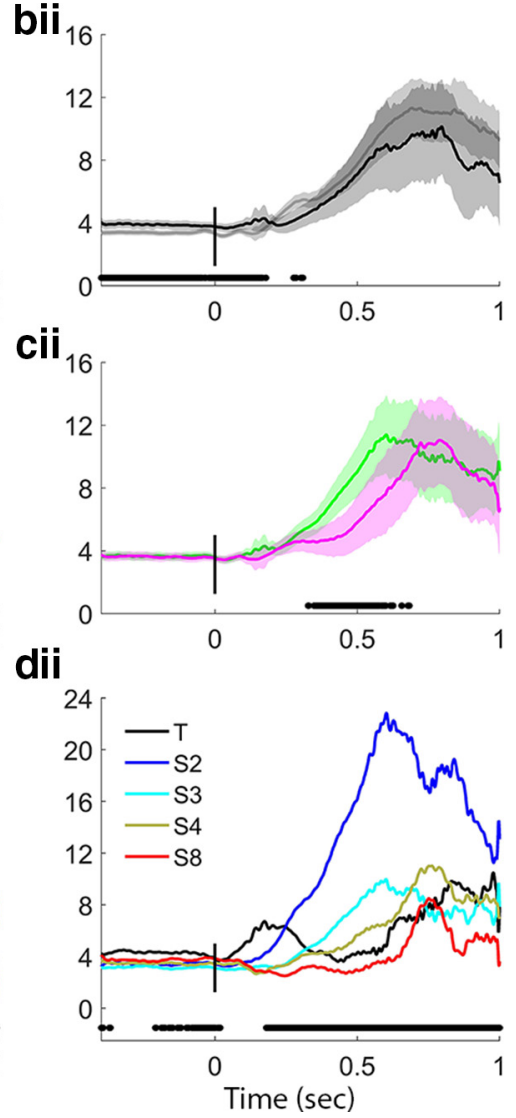

Figure 4. Beta band trace power comparisons. Each row of plots shows a different main effects comparison for Experiments 1 and 2. These values are the outputs of the GLS analysis in which interaction terms were not significant, which means that the task plots in $\boldsymbol{a}$ include values from both $\mathrm{OB}$ and $\mathrm{aPC}$, and the region plots in $\boldsymbol{b}$ include data from both GNG and TAC, etc. Black points below the plots indicate significance markers $(p<0.05)$ from GLS analysis on the time slice. We consider as significant only effects with a large number of consecutive significance markers. ai, aii, Task effects are significant before the nose-poke and in the early odor sampling period in Experiment 1, with TAC exhibiting stronger beta power. bi, bii, Brain region effects are significant in both experiments before nose-poke and in Experiment 1 during the period of strong beta during odor sampling, with stronger beta in the aPC. ci, cii, odors (A or B) show no effects on beta power in Experiment 1, but beta increase starts earlier for odor A in Experiment 2 (left vs right in TAC, CS ${ }^{+}$vs CS ${ }^{-}$in GNG, respectively). di, dii, 0dor sets produced differences in beta power during the odor sampling period in both experiments and before the nose-poke in Experiment 2. The training odor set produced negligible beta in Experiment 1 and increased beta in Experiment 2. The extreme odor set produced very little beta. T, Training odor set; E, extreme odor set; $S \#$, numbered odor sets (see Table 1). Power values are smoothed in time over a 50 point ( $\sim 25 \mathrm{~ms}$ ) window.

full preodor and odor periods, followed by trace analysis to look at the temporal dynamics.

\section{Full gamma band $(62-110 \mathrm{~Hz})$}

Task differences were limited for the gamma band. The TAC task produced more gamma than GNG but only in the preodor period in Experiment 1 (Table 3; Fig. $3 a ; F_{(1,1243)}=9.54, p=0.0021$ ). The difference was in the same direction in Experiment 2 during the preodor period, but it was not significant $(p>0.05)$. Gamma power did not differ significantly by task during the odor period in either experiment.
Gamma was larger in the OB than in the aPC in both experiments and periods (Table 3; Fig. 3b; Experiment 1 (odor): $F_{(1,1243)}=148.59, p<0.0001$; Experiment 1 (preodor): $F_{(1,1243)}=134.62, p<$ 0.0001; Experiment 2 (odor): $F_{(1,294)}=$ 42.35, $p<0.0001$; Experiment 2 (preodor): $\left.F_{(1,294)}=17.85, p<0.0001\right)$. This is in line with previous research that has consistently shown larger gamma in the OB than in the aPC (Martin et al., 2004a; Beshel et al., 2007).

Odor set component (A, B) did not affect the amount of gamma, but gamma power did depend on the odor set in Experiment 1 for both the preodor and odor periods (Table 3; odor $F_{(6,1243)}=5.70, p<$ 0.0001 ; preodor: $F_{(6,1243)}=4.14, p=$ $0.0004)$. Post hoc analysis showed that in the odor period S3 had larger gamma than S5 (Bonferroni correction $\alpha=0.0024$ ). No pairwise comparisons were significant in the preodor period. When rats performed both tasks (Experiment 2), gamma power did not vary by odor set.

Gamma power decreased significantly with longer sampling times during the odor period in Experiment $1\left(F_{(1,1243)}=\right.$ $7.69, p=0.0056)$. The direction was also negative in Experiment 2 but was not significant. Preodor gamma power did not predict sampling duration in either experiment.

In Experiment 1 during the preodor period, increases in gamma power may correlate with better performance. The GLS coefficient was not significant ( $p=$ $0.1046)$, but the Wald $F$ test was $\left(F_{(1,1243)}\right.$ $=3.97, p=0.0466)$. Building a model without the performance term was not significantly different from the full model $(p=0.10)$, which suggests that performance, if significant, is a small effect. The estimated coefficients for the odor period in Experiment 1 and the preodor and odor periods in Experiment 2 were all positive, but not significant.

Summarizing the gamma band session level analysis, we find that the largest and most persistent effect is the larger gamma power in OB compared with aPC (Table 3; Fig. 3). Other effects were smaller and less consistent across the two experiments. When rats knew only one task (Experiment 1), TAC rats produced larger preodor gamma than GNG rats, and there was some variability of gamma power across odor sets, decreased gamma with increased sampling time, and some increase in performance with increased preodor gamma. These effects disappeared when rats knew both tasks (Experiment 2).

Full gamma band power trace analysis shows fast changes over the behavioral epochs (Fig. 5). There is an abrupt surge in gamma power at nose-poke-on. The sniffing pattern is also clearly seen within many of these plots as brief increases and decreases in 
gamma power in the early sampling period; each sniff corresponds to a gamma event in individual trials (Rojas-Líbano et al., 2014), which points to stereotyped behavior across animals and sessions. This pattern is most clearly defined in GNG compared with TAC rats (Fig. 5a). There is a marked difference in gamma power between the $\mathrm{OB}$ and $\mathrm{aPC}$ for the entire analysis period in Experiment 1 (Fig. 5bi). This difference is present in Experiment 2, but there is a large portion of the later half of the odor-period where the power was not different between the two structures (Fig. 5bii). There were no differences in gamma power between component odors $A$ and B (Fig. 5c), and the individual odor set effects were not consistent between the experiments (Fig. $5 d$ ). The extreme odor set was used only in Experiment 1, and it shows high gamma power that builds with later sniffs than the other odor sets, accompanied by low beta power (Figs. 1, $4 d$, $5 d)$.

\section{Slow gamma $(62-80 \mathrm{~Hz})$}

The slow or low-frequency range of the gamma band has been provisionally attributed to mitral cells, due to its position in the later part of the sniff cycle (Fig. $1 a, b$ ) (Manabe and Mori, 2013). Slow gamma power is generally larger in amplitude than fast gamma power, matching expectations from the $1 / f$ falloff of power in the frequency spectrum (Kay, 2015), so it is reasonable to expect that slow gamma power will recapitulate most of the results from the full band.

Task differences in slow gamma power were significant only in Experiment 1; TAC rats showed more power than GNG rats during the preodor period (Table 4; Fig. $3 a ; F_{(1,1243)}=12.29$, $p=0.0005)$.

As with the entire gamma band, we found that there was significantly larger slow gamma in the $\mathrm{OB}$ than in the $\mathrm{aPC}$ during the odor period in both experiments and during the preodor period in Experiment 1 (Table 4; Fig. $3 b$; Experiment 1 (odor): $F_{(1,1243)}=108.40, p<0.0001$; Experiment 1 (preodor): $F_{(1,1243)}=83.09, p<0.0001$; Experiment 2 (odor): brain region, $F_{(1,294)}=21.25, p<0.0001$ ). The difference was not significant in the preodor period in Experiment 2, but it was in the same direction. This result largely replicates the results from the full gamma band.

Slow gamma power did not differ by odor component (A, $B)$, but the power did vary by odor set during both preodor and odor periods in Experiment 1 (odor: $F_{(6,1243)}=6.78, p<$ 0.0001 ; preodor: $\left.F_{(6,1243)}=4.96, p<0.0001\right)$. Post hoc analysis showed more slow gamma in S3 than S5 during the odor period (Bonferroni correction, $\alpha=0.0024 ; p=0.0007$ ). There were no significant pairwise comparisons in the preodor period for either experiment.
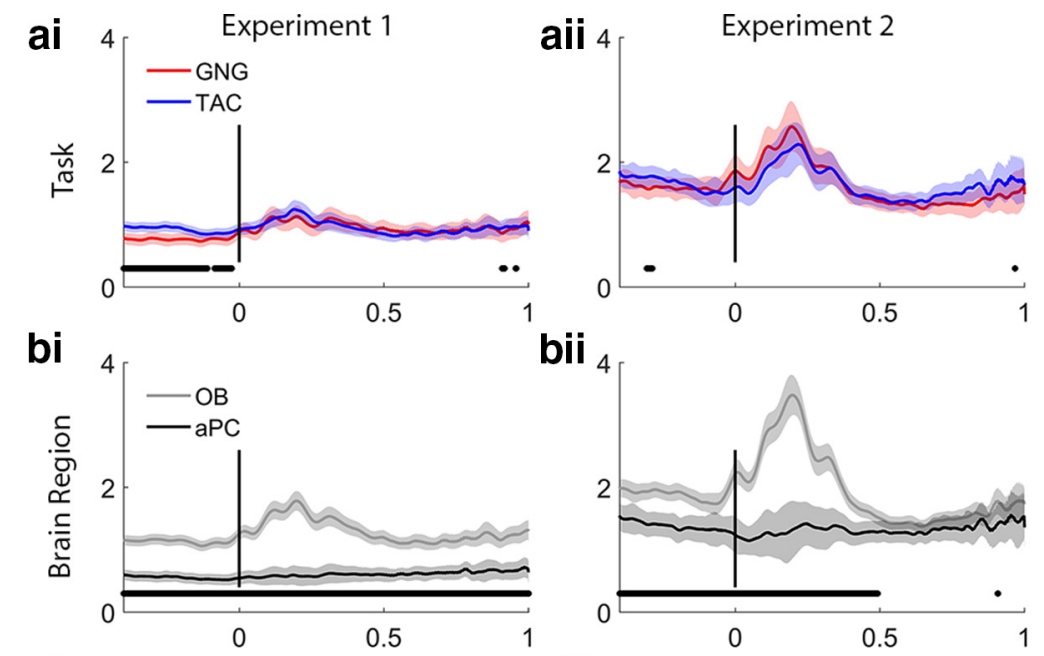

bii
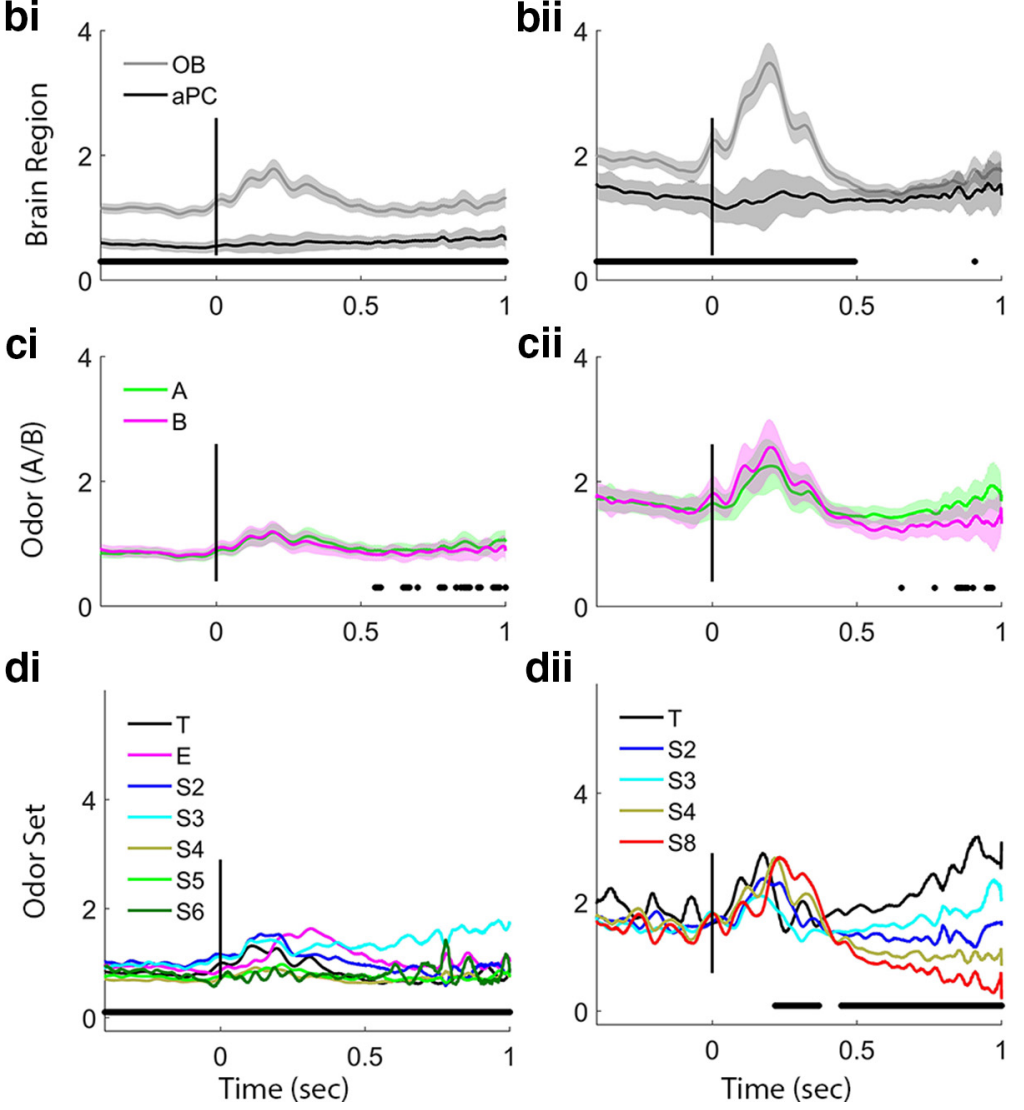

dii

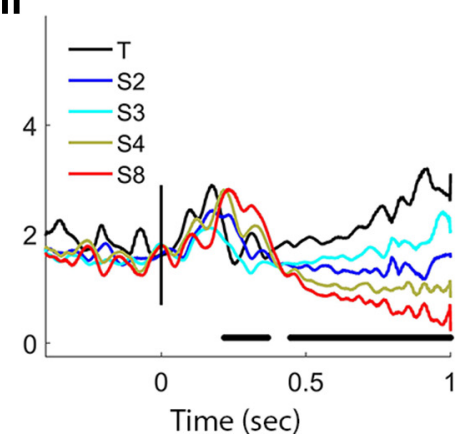

Figure 5. Gamma band trace power comparisons. Plots arrayed as in Figure 4. ai, aii, Task effects are significant before the nose-poke in Experiment 1, with TAC exhibiting stronger gamma power. bi, bii, Brain region effects are significant in both

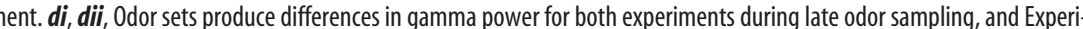
ment 1 shows a significant effect of odor set during the entire preodor and odor periods. Legends as in Figure $4 d$. Power values are smoothed in time over a 50 point ( $\sim 25 \mathrm{~ms})$ window.

Odor period slow gamma power increased slightly over test days within odor sets in Experiment 1 (Table $4 ; F_{(1,1243)}=$ $3.88, p=0.0491 ; \sim 0.02$ unit of slow gamma power increase per day). Performance was also positively correlated with increased slow gamma power during the Experiment 1 odor period $\left(F_{(1,1243)}=3.92, p=0.0480\right.$; Table 4$)$. For each $1 \%$ increase in performance, there is a 0.002 unit increase in slow gamma power. Performance was also positively correlated in Experiment 1 during the preodor period $\left(F_{(1,1234)}=3.92, p=\right.$ $0.0480)$, but the coefficient in the model was not significant $(p=0.4256)$. As a further test to determine whether performance was significant, we built a model without performance, which did not differ significantly from the full model $(p=$ 0.1081 ). This may mean that, if performance is significant, it is a small effect. Finally, sampling duration was negatively correlated with slow gamma power in Experiment 1 during the odor period $\left(F_{(1,1243)}=6.33, p=0.0120\right)$; each $100 \mathrm{~ms}$ of 

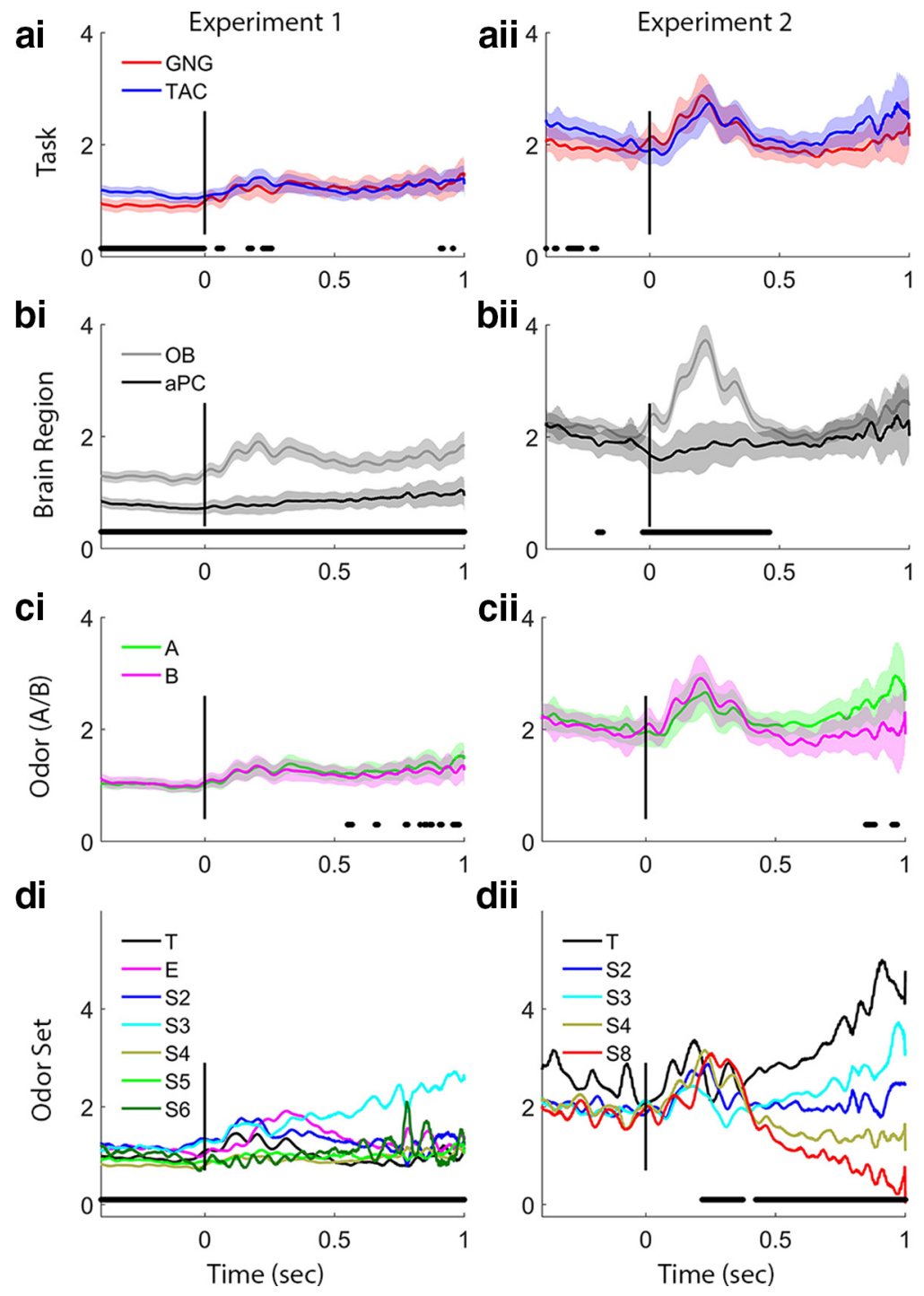

dii

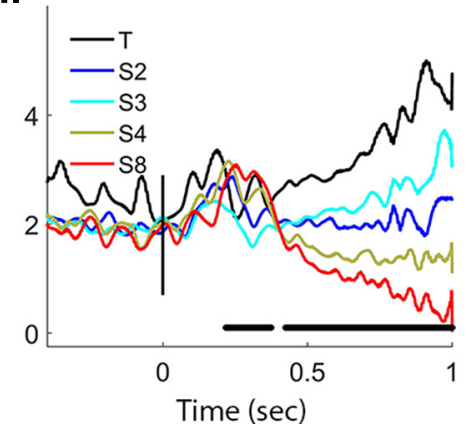

Figure 6. Slow gamma power trace analysis. Plots arrayed as in Figure 4. ai, aii, Task effects are significant before the nose-poke in Experiment 1, with TAC exhibiting stronger slow gamma power. bi, bii, Brain region effects are significant in both experiments during the initial odor sampling period and for Experiment 1 during the entire preodor and odor periods with stronger slow gamma in the $O B$. ci, cii, Odors ( $A$ or $B$ ) show no significant differences in slow gamma in either experiment. di, dii, Odor sets produce differences in slow gamma power during the odor sampling period in both experiments, and Experiment 1 shows a significant effect of odor set during the preodor period as well. Power values are smoothed in time over a 50 point ( $\sim 25 \mathrm{~ms})$ window.

sniffing correlated with a decrease 0.04 unit of slow gamma. These effects were not seen in Experiment 2.

Summarizing the session level statistics for the slow gamma band, we find the results to be similar to the full gamma band. The major effect in this band is the increase in odor period slow gamma in the $\mathrm{OB}$ relative to the aPC in both experiments, and in the preodor period for Experiment 1. Preodor gamma was stronger for TAC than GNG rats in Experiment 1. Also in Experiment 1, gamma varied by odor set, increased over days, predicted increases in performance, and may be negatively correlated with sampling duration in the odor period. These results did not repeat in Experiment 2 where rats knew both tasks.

Slow gamma trace models show a difference in dynamics between the $\mathrm{OB}$ and $\mathrm{aPC}$, with elevated $\mathrm{OB}$ slow gamma during odor sampling and a large increase early in odor sampling, matching what the entire gamma band showed (Figs. 5b, 6b).
In Experiment 1, slow gamma is stronger in the OB than the aPC (Fig. 6bi). In Experiment 2, OB slow gamma is only stronger during the early odor period (Fig. 6bii). Only Experiment 1 shows task differences in slow gamma and only in the preodor period with TAC stronger than GNG (Fig. 6ai). In Experiment 1 , throughout both the preodor and odor periods, there are significant odor set differences in slow gamma power (Fig. 6di). In Experiment 2, the odor set differences occur only during the later part of the odor period (Fig. 6dii).

\section{Fast gamma $(80-110 \mathrm{~Hz})$}

The fast or high-frequency range of the gamma band has been provisionally attributed to tufted cells, due to its position in the early part of the sniff cycle (Fig. 1b) (Manabe and Mori, 2013). Our analyses show some differences between slow and fast gamma.

Similar to slow gamma, fast gamma power was significantly larger in TAC than GNG during the preodor period in Experiment 1 (Table 5; Fig. $3 a ; F_{(1,1243)}=$ $5.69, p=0.0172)$.

As seen above in broad band and slow gamma, fast gamma was larger in the $\mathrm{OB}$ than in the aPC during the odor and preodor period in both experiments (Table 5; Fig. $3 b$; Experiment 1 (odor): $F_{(1,1243)}=$ 185.48, $p<0.0001$; Experiment 1 (preodor): $F_{(1,1243)}=194.94, p<0.0001$; Experiment 2 (odor): $F_{(1,294)}=70.65, p<0.0001$; Experiment 2 (preodor): $F_{(1,294)}=66.03$, $p<0.0001)$.

Fast gamma power did not vary by odor component $(A, B)$, but it did vary by odor set in Experiment 1 during both the odor and preodor period (Table 5; odor: $F_{(6,1243)}=4.06, p=0.0005$; preodor: $\left.F_{(6,1243)}=3.02, p=0.0062\right)$. Post hoc analysis showed no significant pairwise comparisons.

During the odor period in both experiments, sampling duration was negatively correlated with fast gamma power, such that longer sampling times were associated with decreases in fast gamma power (Table 5; Experiment 1: $F_{(1,1243)}=6.50, p=$ 0.0109; Experiment 2: $\left.F_{(1,294)}=7.14, p=0.0079\right)$.

In both experiments, preodor increases in fast gamma power correlated with increased performance (Table 5; Experiment 1: $F_{(1,1243)}=3.86, p=0.0496$; Experiment 2: $F_{(1,294)}=5.56, p=$ 0.0190 ). The effect in Experiment 1 may be quite weak because the estimated coefficient is not significant when viewed in model results ( $p=0.1051)$ but is significant with the Wald's $F$ test. Building a new model for Experiment 1 without the performance term was not significantly different from the full model ( $p=0.11$ ), which suggests that, if performance is significant in that experiment, it is a small effect.

Summarizing session-level statistics for the fast gamma band shows a more consistent picture across the two experiments than 
for the other bands. Fast gamma power is stronger in the $\mathrm{OB}$ than the aPC in both preodor and odor periods for Experiment 1 and Experiment 2. In both experiments, longer sampling duration during the odor period correlated with decreases in fast gamma power, suggesting that later periods of odor sampling may not engage fast gamma. In both experiments, increased performance was correlated with increases in preodor fast gamma, but only weakly so in Experiment 1. In Experiment 1, TAC showed stronger preodor fast gamma than GNG, and there was some variability in fast gamma during odor sampling across odor sets.

Trace models show both similarities and differences to the full and slow gamma bands as oscillations change throughout the behavioral epoch (Fig. 7). Similar to the full gamma and slow gamma bands, in both experiments there is significantly more fast gamma power in the $\mathrm{OB}$ than in the aPC (Fig. 7b); for both experiments, the difference persists throughout the entire analysis period for this frequency band. TAC produces stronger fast gamma than GNG for much of the preodor period in Experiment 1 (Fig. 7ai). High-frequency gamma power varies by odor set during the entire preodor and odor periods in Experiment 1 and during the early and late odor sampling periods in Experiment 2 (Fig. 7d). The extreme odor set shows the same late-onset sustained high power for the high-frequency gamma band as it does for low gamma and the full band (Fig. 7di).

\section{Coherence}

Coherence measures represent shared activity with consistent phase relationships between the OB and aPC. Coherence is independent of power within either area, and thus may show different effects than power within each of the brain regions, as we have discussed previously (Kay and Beshel, 2010). Overall, coherence analysis showed fewer significant differences across factors than power analysis, but there were different patterns for the two experiments. Because most of the comparisons within each band were not significant, we present the statistics on significant results in the text rather than in tables.

In Experiment 1, beta band OB-aPC coherence was stronger for the TAC than the GNG task during the preodor period (Fig. $3 c ; F_{(1,597)}=4.60, p=0.0323$ ). Experiment 1 gamma band coherence was stronger in TAC than GNG during both the preodor and odor periods (gamma(odor): $F_{(1,597)}=5.21, p$ $=0.0229$; gamma (preodor): $F_{(1,597)}=7.25, p=0.0073$; slow gamma(odor): $F_{(1,597)}=5.58, p=0.0185$; slow gamma (preodor): $F_{(1,597)}=0.0057$; fast gamma (odor): $F_{(1,597)}=4.76, p=$ 0.0295; fast gamma (preodor): $\left.F_{(1,597)}=6.75, p=0.0096\right)$.

The task differences that were present in Experiment 1 were not present in Experiment 2. In Experiment 2, beta band coher- ence did not differ for any of the factors, but there were several significant effects on gamma band coherence. Preodor and odor period gamma band coherence decreased with increased sampling duration (preodor: sampling duration coefficient $(\mathrm{SE})=$ -0.0001 (0.00002) power/ms; $F_{(1,77)}=13.55, p=0.0004$; odor: sampling duration coefficient $(\mathrm{SE})=-0.00006$ (0.00002) pow$\left.\mathrm{er} / \mathrm{ms} ; F_{(1,77)}=11.79, p=0.0010\right)$ ). The amount of decrease was small; in the preodor period, each $100 \mathrm{~ms}$ of subsequent sampling was correlated with a decrease of 0.002 unit of gamma $z$-coherence. In the odor period, each $100 \mathrm{~ms}$ of sampling was correlated with a decrease of 0.006 unit of gamma $z$-coherence.

Fast gamma coherence during both preodor and odor periods increased over days within odor sets in Experiment 2 (preodor: day coefficient $(\mathrm{SE})=0.007(0.003)$ power $/ \mathrm{d} ; F_{(1,77)}=4.95, p=0.0290$; odor: day coefficient $(\mathrm{SE})=0.006(0.003)$ power/d; $F_{(1,77)}=4.08$, $p=0.0468$ ).

Trace coherence models examine gamma and beta coherence over time and show that coherence relationships are tem- 

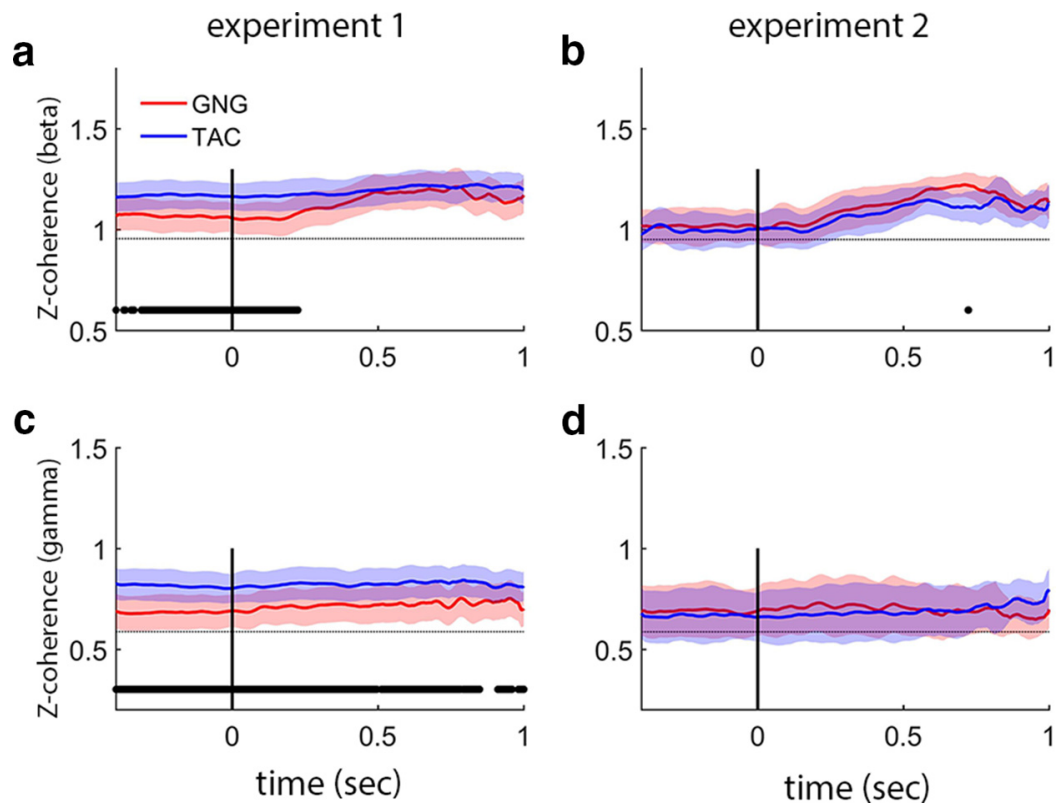

Figure 8. Coherence between $\mathrm{OB}$ and aPC is modulated by task and experimental context. Trace coherence analysis for beta and gamma bands with $95 \%$ confidence bounds. $\boldsymbol{a}, \boldsymbol{b}$, Beta band. $\boldsymbol{a}$, In Experiment 1, TAC coherence is significantly greater than GNG until $250 \mathrm{~ms}$ of odor sampling (when large beta oscillations appear, see Fig. 3; NB coherence measures are independent of power). $\boldsymbol{b}$, In Experiment 2, TAC coherence is decreased relative to Experiment 1 in the preodor and early odor periods. There is no task difference in coherence in the beta band during Experiment 2. $\boldsymbol{c}, \boldsymbol{d}$, Gamma band. $\boldsymbol{c}$, In Experiment 1, TAC coherence is stronger than GNG for the entire analysis period. $\boldsymbol{d}$, In Experiment 2, TAC coherence values decreased from levels in Experiment 1 showing no task difference in Experiment 2 ( $($-coherence is the arctanh of coherence; see Materials and Methods). Scales in $\boldsymbol{a}, \boldsymbol{b}$ are different from $\boldsymbol{c}, \boldsymbol{d}$ to better visualize the different coherence values for beta and gamma oscillations, respectively. Gray dotted horizontal lines indicate chance levels for each band and experiment from shuffled values with $95 \%$ confidence bounds (thickness of line). Power values are smoothed in time over a 100 point $(\sim 50 \mathrm{~ms})$ window.

porally more stable than the momentary changes in power within a frequency band (Fig. 8). In Experiment 1, beta coherence is constant for TAC and higher than GNG until the 250 ms point during odor sampling (Fig. $8 a$ ); GNG beta coherence starts lower and reaches a maximum at $\sim 500 \mathrm{~ms}$. Gamma band coherence is constant throughout Experiment 1 and stronger for TAC than GNG (Fig. 7c). In Experiment 2, beta coherence starts lower, increases beginning at $\sim 200 \mathrm{~ms}$ of odor sampling, and reaches a maximum after $500 \mathrm{~ms}$ of odor sampling for both tasks (Fig. 8b); gamma coherence is constant in Experiment 2 (Fig. $8 d$ ). The experiment differences persist if coherence analysis on Experiment 1 is restricted to the same rats that performed Experiment 2 (data not shown), suggesting a systemwide connectivity difference between the two experimental contexts.

\section{Comparing dynamics across bands}

To more closely inspect the changing picture of slow and fast gamma dynamics, we computed a ratio of slow to fast gamma power for each time point for both experiments (Fig. 9a). This allows us to address the possibility of a trade-off in the circuits responsible for producing gamma over the course of the sampling bout and to determine whether the two gamma bands always work together in the same way. The time courses of the ratio in the $\mathrm{OB}$ and $\mathrm{aPC}$ are the same for both experiments, pointing to a unified dynamical process engaging $\mathrm{OB}$ mitral and tufted cells that underlies both tasks, independent of the context in which the tasks are learned or performed. In the $\mathrm{OB}$, before nose-poke-on and odor sampling, there is a stable slow/fast gamma ratio, which shifts to lower values just before nose-poke-on, representing in- creased fast compared with slow gamma power. This continues for the first two sniffs $(\sim 200 \mathrm{~ms})$, and then a transition begins; slow gamma dominates over fast gamma and builds for the remainder of the analysis period. When we plot all three bands on the same plot for each task, we can see the pattern of give and take between gamma and beta oscillations (Fig. $9 b, c)$. In Experiment 1 for both tasks, starting at $\sim 250 \mathrm{~ms}$ (Fig. $9 \mathrm{bi}$, ci; following the first full sniff after the odor arrives at the sampling port), beta and highfrequency gamma oscillations oppose each other for the remainder of the odor sampling period. In Experiment 2, this transition starts a bit later (Fig. 9bii,cii). In Experiment 2, the mean of the session median end sampling times over all rats and sessions corresponds to the end of the rise in beta power, as if beta represents an accumulating process. Data from an individual rat who performed both experiments show this accumulation effect in both experiments (Fig. 9d).

\section{Reconciling previous studies}

We began these experiments to test a hypothesis that arose after observing different results in two of our previous studies. In our previous GNG study, beta oscillations increased with learning on each new odor set (Martin et al., 2007). In a more complex TAC task than the one presented here, gamma oscillations were associated with learning to discriminate closely related odorants, and beta oscillations, although present, did not track learning (Beshel et al., 2007; Kay and Beshel, 2010). We show representative trials here to compare the timing of gamma and beta oscillations in those studies relative to the results from the current set of experiments (Fig. 10). There were some important differences between those earlier studies and the current one; odor delivery had a longer and less well-controlled delay (estimated to be $150 \mathrm{~ms}$ after nose poke), the odor stayed on for $1.5 \mathrm{~s}$, and we did not track when the rat was in the odor port during the odor period after the initial nose poke. Given these differences, we still see a striking similarity between the earlier studies and this one. Early sniffs after the nose poke are associated with gamma oscillations, followed by beta oscillations. Beta was suppressed for fine, relative to coarse, odor discrimination sessions in the TAC task (Fig. 10c, compare with Figs. 1c, 4di).

\section{Discussion}

In this study, we have addressed the ways in which features of the tasks we use to evaluate a cortical sensory system may impact the types of answers we obtain. We examined the modulatory roles of tasks, learning, and odors on the oscillatory dynamical states that the olfactory system occupies during odor sampling. These two states are defined by gamma $(62-110 \mathrm{~Hz})$ and beta $(15-35 \mathrm{~Hz})$ oscillations of the LFP and map approximately onto the temporal aspects of these oscillations in our previous studies (Figs. 9, 10). We found that many features of a given task, the task itself, and the number of tasks a rat performs can modify the strength of 
ai

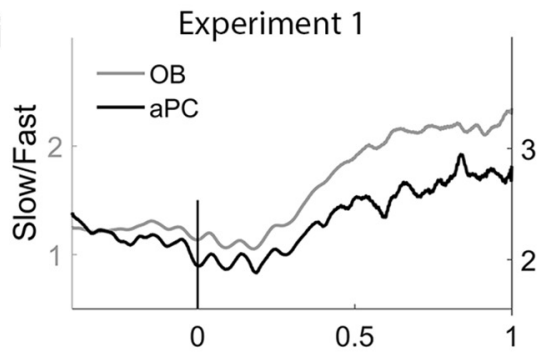

bi

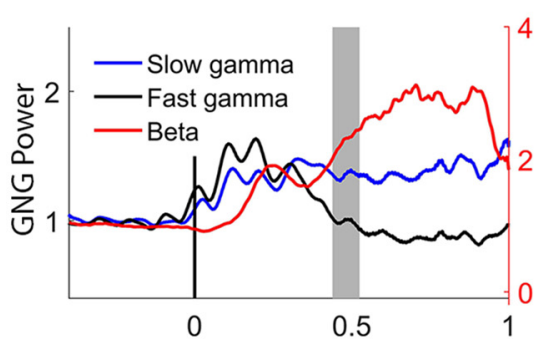

ci

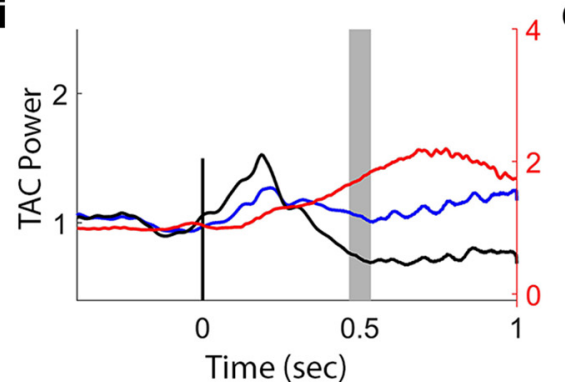

aii

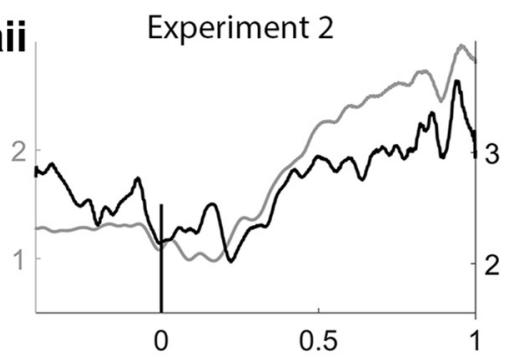

bii

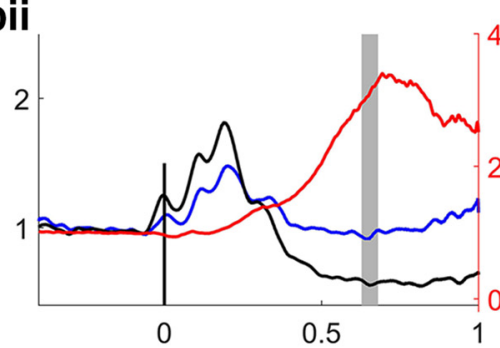

cii

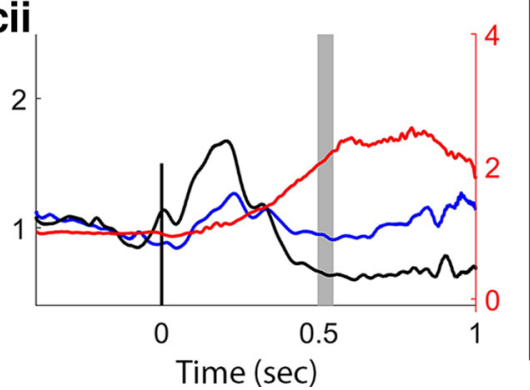

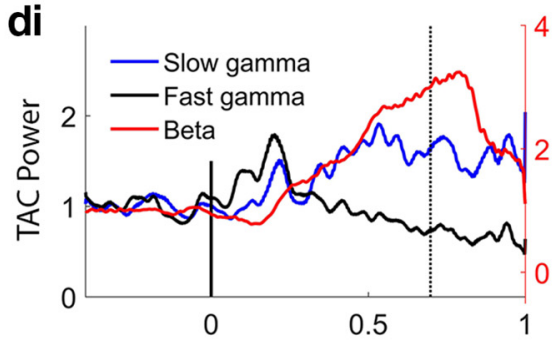

dii
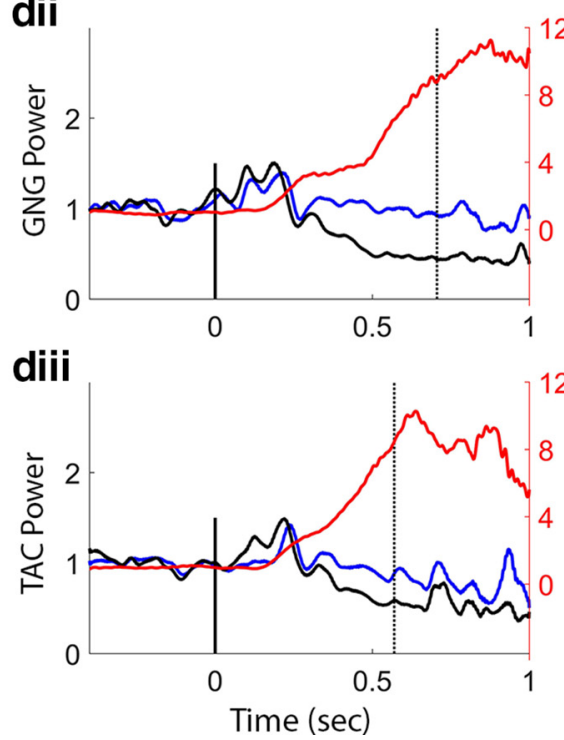

Figure 9. Relative time courses of the frequency bands. $\boldsymbol{a}$, Fast versus slow gamma dynamics in $\mathrm{OB}$ and aPC from Experiments 1 (ai) and 2 (aii); values from $0 \mathrm{~B}$ and aPC are plotted on different scales to emphasize the similarity in dynamics. The aPC has very little high-frequency gamma (compared with the $0 B$, Figs. $5 c, d, 6 c, d$ ), so the ratio of slow to fast gamma is very large in the PC. Both tasks show the same time course of change in slow/fast gamma ratio in the $0 \mathrm{~B}$ and aPC. In the OB, fast gamma power rises during early odor sampling producing a dip in the ratio from 0 to $250 \mathrm{~ms}$, after which slow gamma increases steadily relative to fast gamma power during the rest of the sampling period. In the aPC, a decrease in the ratio (greater fast relative to slow gamma power) briefly during early odor sampling is followed by a return to baseline values. $\boldsymbol{b}$, Comparison of beta, slow gamma, and fast gamma power traces from model estimates in the GNG task (values are normalized to prestimulus baseline values). Beta traces are displayed relative to the right vertical axis for ease of comparison. Left and right $y$-axes align at 1 . Gray shaded vertical bars represent the distribution of end sampling times over all subjects and sessions. Note the opposing changes in power over time in fast gamma and beta. Fast gamma drops well below baseline levels after the initial $250 \mathrm{~ms}$ of odor sampling, whereas slow gamma returns to baseline after this early sampling period, increasing somewhat as sampling persists. Also note the easy identification of the first 3 gamma bursts associated with stereotyped sniffs. $c$, Comparison of beta, slow gamma, and fast gamma power traces from model estimates in the TAC task. The stereotyped gamma bursts/sniffs are not as clearly defined as in the GNG task. In Experiment 2 for both TAC and GNG ( $b i i$, cii), the sampling end time corresponds with the end of the rise in beta power. $\boldsymbol{d}$, Example trace power plots from one rat that completed both experiments. Figure is from data using just $\$ 2$ sessions. di, TAC power traces from Experiment 1 for odor sets S2, S3, and S4. dii, GNG power traces from Experiment 2 for odor sets S2, S3, and S4. diii, TAC power traces from Experiment 2 for the same odor sets. Note the difference in gamma bursts between TAC and GNG. Values are smoothed in time over a 50 point ( $\sim 25 \mathrm{~ms})$ window.

these oscillations. However, beneath this significant modulation by myriad behavioral demands (Tables 2-5; Figs. 4-8) is a stereotyped sequence of oscillatory states that define early and late odor processing (Fig. 9).

During odor sampling, rats produce early OB gamma oscillations locked to stereotyped sniffing for the first 1-3 sniffs after the odor arrives (Figs. 5-7; Tables 3-5). Beta oscillations emerge beginning after 200-250 ms of odor sampling, following early gamma-associated sniffs (Figs. 4, 9). During this later sampling period, the $\mathrm{OB}, \mathrm{PC}$, and other olfactory and limbic areas are strongly coupled in the beta band (Figs. 1c, 8a,b) (Martin et al., 2007; Kay and Beshel, 2010; Cohen et al., 2015a).

This conserved oscillation pattern suggests a set sequence of neurocognitive states that are independently adjusted depending on odors, discrimination context, and task demands. Thus, the differences seen in previous studies, including our own, are likely due to experimental design differences and not to categorical differences between tasks. However, that some tasks can show very different results suggests that task features strongly determine the range of answers that can be obtained from data regarding the underlying system.

\section{Gamma oscillations}

We found two peak frequencies centered at $73 \mathrm{~Hz}$ and $85 \mathrm{~Hz}$ (Fig. 2). A recent hypothesis predicts that tufted cells are associated with respiration-locked fast gamma early in a sniff and mitral cells with slow gamma oscillations occurring later in a sniff (Fukunaga et al., 2012; Igarashi et al., 2012; Payton et al., 2012; Manabe and Mori, 2013). In support of this hypothesis, we find a clear sequence of fast- and slow-gamma oscillations during early odor sampling (Fig. 9b-d, black and blue traces, respectively). Later in odor sampling, fast gamma is suppressed and slow gamma is maintained while beta oscillations dominate (Figs. 6, 7 ), consistent with pathways predominated by mitral and tufted cell projections to the pyriform cortex and olfactory tubercle, respectively.

\section{Beta oscillations}

Beta oscillations showed a single peak frequency centered at 23 $\mathrm{Hz}$ in this study, and beta power modulation occurred in the preodor and odor periods. We found no evidence of learningrelated frequency changes reported elsewhere (Martin et al., 2004b) (Figs. 3, 4). 
a

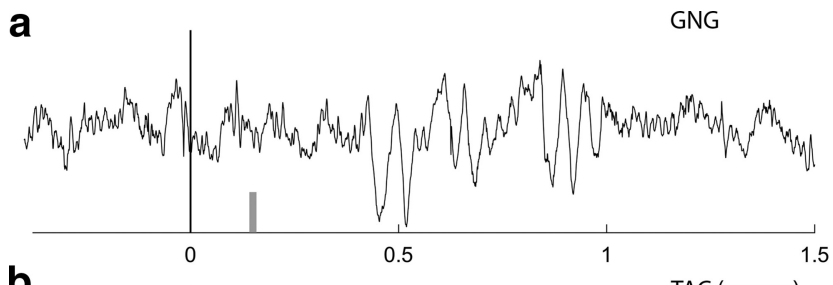

b

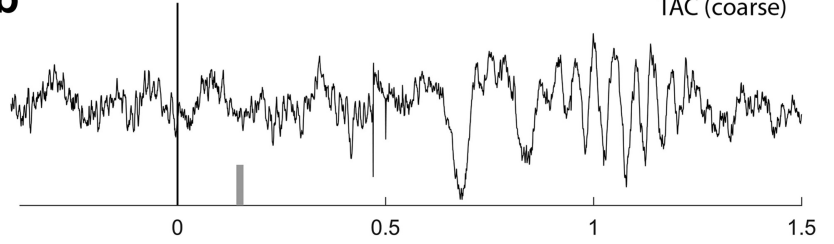

C

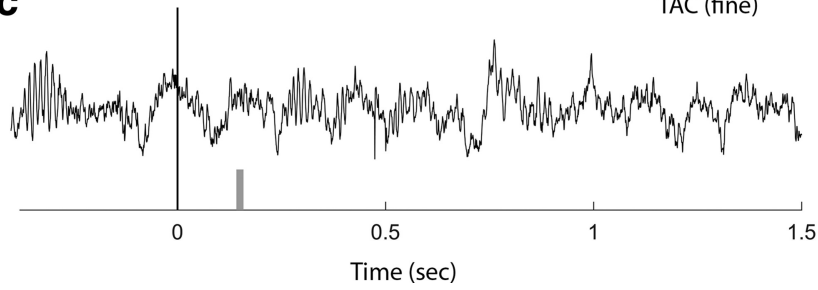

Figure 10. Reconciliation of previous experiments. Example $\mathrm{OB}$ signals for individual trials are shown from two previous studies. Nose-poke to start odor is at $0 \mathrm{~s}$. Short gray vertical bar represents rough estimate of odor arrival time in the setup for these studies ( $\sim 150 \mathrm{~ms}) \cdot \boldsymbol{a}, \mathrm{OB}$ data from a rat sniffing nonanone in a GNG task discriminating from butanone (Martin et al., 2007). The beta oscillation begins at $450 \mathrm{~ms}$ after 3 brief sniffs carrying low-amplitude gamma oscillations. $\boldsymbol{b}, \mathrm{OB}$ data from a rat sniffing nonanone in a TAC task discriminating from butanone (coarse discrimination) (Beshel et al., 2007). The beta oscillation begins at $800 \mathrm{~ms}$ after several brief sniffs carrying irregular and low-amplitude gamma oscillations. C, OB data from the same rat as in $\boldsymbol{b}$, sniffing octanone in a TAC task discriminating from heptanone (fine discrimination). Note the lack of beta and relatively enhanced gamma oscillations.

In the preodor period, beta power differed by task (Experiment 1 ; larger in TAC), brain region (both experiments; larger in aPC), and subsequent sampling duration (both experiments; Figs. 3, 4). Interestingly, the direction of correlation between preodor beta power and subsequent sampling duration was opposite between the experiments (Table 2), which may be due to context differences (i.e., knowing one task or two). Baseline beta power before stimulus onset was much higher in Experiment 1, suggesting a difference between the two experimental contexts in the dynamical structure of the system at baseline. Preodor beta power and TAC beta coherence increases (Fig. 8) may be related to beta band input from the lateral entorhinal cortex associated with preafferent priming (Kay and Freeman, 1998) and odor processing (Chapuis et al., 2013). In Experiment 2, TAC preodor beta coherence is lower than in Experiment 1 and the same as GNG, indicating a system-level change in the TAC task in the context of also knowing GNG.

During the odor period, beta power was modulated by odor set (both experiments; Table 2; Fig. 3a,b), sampling duration (Experiment 1), and odor set component (A vs B, Experiment 2). In both experiments, odor set 2 produced the strongest beta power, and this odor set has the highest vapor pressure values (Table 1). Vapor pressure was not a significant factor in the statistical model, but odor set and vapor pressure factors were highly correlated, suggesting that behavioral context affects the vapor pressure modulation of beta power in appetitive learning, compared with passive odor exposure (Lowry and Kay, 2007).

Odor set and some learning-dependent temporal evolution of beta were clearly evident (Fig. 4d). Beta oscillations were de- pressed for the training odor set in Experiment 1 (Fig. 4di), consistent with our previous study, suggesting that beta power increases only after the first rule transfer to a new odor set (Martin et al., 2007). When the training odors were reintroduced in Experiment 2, beta oscillations were strong in the post-training context (Fig. 4dii). Changes in the PC and hippocampus associated with olfactory rule learning may support this transition (Saar et al., 2012). However, this is the only learning-associated modulation of beta oscillations we observed, in contrast to previous studies (Martin et al., 2004b, 2007; Cohen et al., 2015a,b). Our rats performed more trials per session and learned many more odor sets than in those studies. It is possible that the learning modulation of beta seen in previous studies may be associated with a more extended learning of the task and rule transfer rather than odor association learning per se.

\section{What the oscillations represent}

Neocortical gamma and beta oscillations are thought to be related to attention (Gross et al., 2004; Buzsaki, 2006; Pritchett et al., 2015), and OB gamma has provided insight into mechanism and functionality of gamma in attention (Rojas-Líbano and Kay, 2008). OB gamma is relatively local to the $\mathrm{OB}$, showing low coherence with other brain regions (Fig. 8c,d) (Martin et al., 2007; Kay and Beshel, 2010). In the olfactory system, increased gamma amplitudes represent greater local coherence and precision among principal neurons (Gray and Skinner, 1988; Eeckman and Freeman, 1990; Nusser et al., 2001) and is associated with discriminating similar odors in mammals and insects (Stopfer et al., 1997; Nusser et al., 2001; Beshel et al., 2007). Beta oscillations represent systemwide coherent states (Kay et al., 2009). Preodor increases in all frequency bands for TAC relative to GNG in Experiment 1 may map onto a greater attentional demand in Experiment $1 \mathrm{TAC}$, which produces lower performance. These preodor task differences disappear in the context of Experiment 2, when TAC performance increases.

Gamma power increases seen here were not as dramatic as in our earlier study (Beshel et al., 2007) and did not map exclusively onto odor similarity (Tables $3-5$; Figs. $5-7 d$ ). In the previous study, the TAC task was much more complex than the current one, suggesting that cognitive load and input overlap may contribute to the perceived differences in odor quality and the need for gamma. Gamma increase appears delayed for the extreme odor set (Figs. 5-7di), further suggesting that attentional demands when discriminating very high overlap odors may require not just enhanced gamma but also slower temporal processes that engage more sniffs (Abraham et al., 2004). Gamma power and frequency can also be affected by changes in sniff frequency (Rosero and Aylwin, 2011), but we did not note any systematic differences in LFP respiratory rhythm frequency across odors or tasks.

Beta oscillations depend differently on the same network as gamma. After the initial odor sniffs until the end of the sampling bout, high-frequency OB gamma oscillations decrease and systemwide beta oscillations increase (Fig. $9 b-d$ ), suggesting that the physiological circumstances that favor beta oscillations may prohibit high-frequency gamma. It is possible that the presumed mitral cell slower gamma oscillations and the different targets of mitral and tufted cells contribute to a state change as beta oscillations are initiated in the circuit (Haberly and Price, 1977; Igarashi et al., 2012). Two recent modeling studies argue that switches from gamma to beta oscillations are driven by changes in $\mathrm{OB}$ granule cell excitability due to combined centrifugal and sensory inputs. One models beta oscillations as mediated by the long 
decay times of increased NMDA and voltage-dependent calcium currents in granule cells (Osinski and Kay, 2016). The other relies on transitions from nonspiking to spiking states, which gives strong pulses of inhibition to mitral cells (David et al., 2015).

Are beta oscillations necessary for odor discrimination? We know that, with one full sniff after arrival of the odor $(200 \mathrm{~ms}$ in our apparatus), rats and mice usually identify odors above chance; after 1 or 2 additional sniffs, performance increases in these tasks and others (Rinberg et al., 2006; Frederick et al., 2011; Rojas-Líbano and Kay, 2012). Longer sniffing times include beta oscillations. Because of beta's late-onset, wide system involvement and being unnecessary for performance above chance, we infer that gamma, not beta, oscillations are the basic sensory or perceptual event. Beta oscillations are often the only consistently coherent band across brain regions in many cortical systems (Kay et al., 2009; Engel and Fries, 2010), which has led to the idea that beta oscillations allow communication and transfer of information within and between cortical areas (Rubino et al., 2006; Gourévitch et al., 2010; Kay and Beshel, 2010). We suggest that olfactory beta oscillations are better associated with higher cognitive processes, such as making choices or initiating actions (Hermer-Vazquez et al., 2007) or even with conscious awareness (Gaillard et al., 2009).

In conclusion, the results reported here suggest that the mix of gamma followed by beta oscillations varies dependent on particular cognitive demands, but the two oscillatory modes likely represent different cognitive states occurring in defined sequence and give us access to an underlying unified functional framework consistent with a perception-action loop (Freeman, 1975, 1999). This result comes only after challenging the system with multiple tasks and stimulus sets and reinforces the idea that cognitive states reach down into relatively peripheral sensory cortical systems, and these effects can vary dramatically depending on context.

\section{References}

Abraham NM, Spors H, Carleton A, Margrie TW, Kuner T, Schaefer AT (2004) Maintaining accuracy at the expense of speed: stimulus similarity defines odor discrimination time in mice. Neuron 44:865-876. CrossRef Medline

Beshel J, Kopell N, Kay LM (2007) Olfactory bulb gamma oscillations are enhanced with task demands. J Neurosci 27:8358-8365. CrossRef Medline

Bokil H, Andrews P, Kulkarni JE, Mehta S, Mitra PP (2010) Chronux: a platform for analyzing neural signals. J Neurosci Methods 192:146-151. CrossRef Medline

Bressler SL, Freeman WJ (1980) Frequency analysis of olfactory system EEG in cat, rabbit, and rat. Electroencephalogr Clin Neurophysiol 50:19-24. CrossRef Medline

Brillinger DR (1981) Time series: data analysis and theory. San Francisco: Holden-Day.

Buzsaki G (2006) Rhythms of the Brain. New York: Oxford UP.

Chapuis J, Cohen Y, He X, Zhang Z, Jin S, Xu F, Wilson DA (2013) Lateral entorhinal modulation of piriform cortical activity and fine odor discrimination. J Neurosci 33:13449-13459. CrossRef Medline

Cohen Y, Putrino D, Wilson DA (2015a) Dynamic cortical lateralization during olfactory discrimination learning. J Physiol 593:1701-1714. CrossRef Medline

Cohen Y, Wilson DA, Barkai E (2015b) Differential modifications of synaptic weights during odor rule learning: dynamics of interaction between the piriform cortex with lower and higher brain areas. Cereb Cortex 25:180191. CrossRef Medline

Cury KM, Uchida N (2010) Robust odor coding via inhalation-coupled transient activity in the mammalian olfactory bulb. Neuron 68:570-585. CrossRef Medline

David F, Courtiol E, Buonviso N, Fourcaud-Trocmé N (2015) Competing mechanisms of gamma and beta oscillations in the olfactory bulb based on multimodal inhibition of mitral cells over a respiratory cycle. eNeuro 2:ENEURO.0018-15.2015. Medline

Doucette W, Restrepo D (2008) Profound context-dependent plasticity of mitral cell responses in olfactory bulb. PLoS Biol 6:e258. CrossRef Medline

Eeckman FH, Freeman WJ (1990) Correlations between unit firing and EEG in the rat olfactory system. Brain Res 528:238-244. CrossRef Medline

Engel AK, Fries P (2010) Beta-band oscillations-signalling the status quo? Curr Opin Neurobiol 20:156-165. CrossRef Medline

Frederick DE, Rojas-Líbano D, Scott M, Kay LM (2011) Rat behavior in go/no-go and two-alternative choice odor discrimination: differences and similarities. Behav Neurosci 125:588-603. CrossRef Medline

Freeman WJ (1975) Mass action in the nervous system. San Diego: Academic.

Freeman WJ (1999) Consciousness, intentionality, and causality. J Conscious Stud 6:143-172.

Freeman WJ (2003) The wave packet: an action potential for the 21st century. J Integr Neurosci 2:3-30. CrossRef Medline

Freeman WJ, Schneider W (1982) Changes in spatial patterns of rabbit olfactory EEG with conditioning to odors. Psychophysiology 19:44-56. CrossRef Medline

Friedrich RW (2006) Mechanisms of odor discrimination: neurophysiological and behavioral approaches. Trends Neurosci 29:40-47. CrossRef Medline

Fukunaga I, Berning M, Kollo M, Schmaltz A, Schaefer AT (2012) Two distinct channels of olfactory bulb output. Neuron 75:320-329. CrossRef Medline

Gaillard R, Dehaene S, Adam C, Clémenceau S, Hasboun D, Baulac M, Cohen L, Naccache L (2009) Converging intracranial markers of conscious access. PLoS Biol 7:e61. CrossRef Medline

Gamble KR, Smith DW (2009) Discrimination of "odorless" mineral oils alone and as diluents by behaviorally trained mice. Chem Senses 34:559_ 563. CrossRef Medline

Gourévitch B, Kay LM, Martin C (2010) Directional coupling from the olfactory bulb to the hippocampus during a go/no-go odor discrimination task. J Neurophysiol 103:2633-2641. CrossRef Medline

Gray CM, Skinner JE (1988) Centrifugal regulation of neuronal activity in the olfactory bulb of the waking rabbit as revealed by reversible cryogenic blockade. Exp Brain Res 69:378-386. Medline

Gross J, Schmitz F, Schnitzler I, Kessler K, Shapiro K, Hommel B, Schnitzler A (2004) Modulation of long-range neural synchrony reflects temporal limitations of visual attention in humans. Proc Natl Acad Sci U S A 101: 13050-13055. CrossRef Medline

Haberly LB, Price JL (1977) Axonal projection patterns of mitral and tufted cells of olfactory-bulb in rat. Brain Res 129:152-157. CrossRef Medline

Hermer-Vazquez R, Hermer-Vazquez L, Srinivasan S, Chapin JK (2007) Beta- and gamma-frequency coupling between olfactory and motor brain regions prior to skilled, olfactory-driven reaching. Exp Brain Res 180: 217-235. CrossRef Medline

Igarashi KM, Ieki N, An M, Yamaguchi Y, Nagayama S, Kobayakawa K, Kobayakawa R, Tanifuji M, Sakano H, Chen WR, Mori K (2012) Parallel mitral and tufted cell pathways route distinct odor information to different targets in the olfactory cortex. J Neurosci 32:7970-7985. CrossRef Medline

Kay LM (2003) Two species of gamma oscillations in the olfactory bulb: dependence on behavioral state and synaptic interactions. J Integr Neurosci 2:31-44. CrossRef Medline

Kay LM (2011) Olfactory coding: random scents make sense. Curr Biol 21: R928-R929. CrossRef Medline

Kay LM (2015) Olfactory system oscillations across phyla. Curr Opin Neurobiol 31:141-147. CrossRef Medline

Kay LM, Beshel J (2010) A beta oscillation network in the rat olfactory system during a 2-alternative choice odor discrimination task. J Neurophysiol 104:829-839. CrossRef Medline

Kay LM, Freeman WJ (1998) Bidirectional processing in the olfactorylimbic axis during olfactory behavior. Behav Neurosci 112:541-553. CrossRef Medline

Kay LM, Laurent G (1999) Odor- and context-dependent modulation of mitral cell activity in behaving rats. Nat Neurosci 2:1003-1009. CrossRef Medline

Kay LM, Lazzara P (2010) How global are olfactory bulb oscillations? J Neurophysiol 104:1768-1773. CrossRef Medline 
Kay LM, Beshel J, Martin C (2006) When good enough is best. Neuron 51:277-278. CrossRef Medline

Kay LM, Beshel J, Brea J, Martin C, Rojas-Líbano D, Kopell N (2009) Olfactory oscillations: the what, how and what for. Trends Neurosci 32: 207-214. CrossRef Medline

Kepecs A, Uchida N, Mainen ZF (2007) Rapid and precise control of sniffing during olfactory discrimination in rats. J Neurophysiol 98:205-213. CrossRef Medline

Laurent G, Wehr M, Davidowitz H (1996) Temporal representations of odors in an olfactory network. J Neurosci 16:3837-3847. Medline

Lowry CA, Kay LM (2007) Chemical factors determine olfactory system beta oscillations in waking rats. J Neurophysiol 98:394-404. CrossRef Medline

Manabe H, Mori K (2013) Sniff rhythm-paced fast and slow gamma oscillations in the olfactory bulb: relation to tufted and mitral cells and behavioral states. J Neurophysiol 110:1593-1599. CrossRef Medline

Martin C, Ravel N (2014) Beta and gamma oscillatory activities associated with olfactory memory tasks: different rhythms for different functional networks? Front Behav Neurosci 8:218. CrossRef Medline

Martin C, Gervais R, Chabaud P, Messaoudi B, Ravel N (2004a) Learninginduced modulation of oscillatory activities in the mammalian olfactory system: the role of the centrifugal fibres. J Physiol Paris 98:467-478. CrossRef Medline

Martin C, Gervais R, Hugues E, Messaoudi B, Ravel N (2004b) Learning modulation of odor-induced oscillatory responses in the rat olfactory bulb: a correlate of odor recognition? J Neurosci 24:389-397. CrossRef Medline

Martin C, Gervais R, Messaoudi B, Ravel N (2006) Learning-induced oscillatory activities correlated to odour recognition: a network activity. Eur J Neurosci 23:1801-1810. CrossRef Medline

Martin C, Beshel J, Kay LM (2007) An olfacto-hippocampal network is dynamically involved in odor-discrimination learning. J Neurophysiol 98: 2196-2205. CrossRef Medline

Neville KR, Haberly LB (2003) Beta and gamma oscillations in the olfactory system of the urethane-anesthetized rat. J Neurophysiol 90:3921-3930. CrossRef Medline

Nusser Z, Kay LM, Laurent G, Mody I, Homanics GE (2001) Disruption of GABA(A) receptors on GABAergic interneurons leads to increased oscillatory power in the olfactory bulb network. J Neurophysiol 86:2823-2833. Medline

Osinski BL, Kay LM (2016) Granule cell excitability mediates gamma and beta oscillations in a model of the dendrodendritic microcircuit. J Neurophysiol. Advance online publication. doi: 10.1152/jn.00988.2015. CrossRef

Payton CA, Wilson DA, Wesson DW (2012) Parallel odor processing by two anatomically distinct olfactory bulb target structures. PLoS One 7:e34926. CrossRef Medline
Pinheiro JC, Bates DM (2000) Mixed-effects models in S and S-PLUS. New York: Springer.

Pinheiro J, Bates D, DebRoy S, Sarkar D, R Core Team (2016). nlme: linear and nonlinear mixed effects models. $\mathrm{R}$ package version 3.1-124, http://CRAN.R-project.org/package $=$ nlme.

Pritchett DL, Siegle JH, Deister CA, Moore CI (2015) For things needing your attention: the role of neocortical gamma in sensory perception. Curr Opin Neurobiol 31:254-263. CrossRef Medline

Rajan R, Clement JP, Bhalla US (2006) Rats smell in stereo. Science 311: 666-670. CrossRef Medline

Rinberg D, Koulakov A, Gelperin A (2006) Speed-accuracy tradeoff in olfaction. Neuron 51:351-358. CrossRef Medline

Rubino D, Robbins KA, Hatsopoulos NG (2006) Propagating waves mediate information transfer in the motor cortex. Nat Neurosci 9:1549-1557. CrossRef Medline

Rojas-Líbano D, Kay LM (2008) Olfactory system gamma oscillations: the physiological dissection of a cognitive neural system. Cogn Neurodyn 2:179-194. CrossRef Medline

Rojas-Líbano D, Kay LM (2012) Interplay between sniffing and odorant sorptive properties in the rat. J Neurosci 32:15577-15589. CrossRef Medline

Rojas-Líbano D, Frederick DE, Egaña JI, Kay LM (2014) The olfactory bulb theta rhythm follows all frequencies of diaphragmatic respiration in the freely behaving rat. Front Behav Neurosci 8:214. CrossRef Medline

Rosero MA, Aylwin ML (2011) Sniffing shapes the dynamics of olfactory bulb gamma oscillations in awake behaving rats. Eur J Neurosci 34: 787-799. CrossRef Medline

Saar D, Reuveni I, Barkai E (2012) Mechanisms underlying rule learninginduced enhancement of excitatory and inhibitory synaptic transmission. J Neurophysiol 107:1222-1229. CrossRef Medline

Schaefer AT, Margrie TW (2007) Spatiotemporal representations in the olfactory system. Trends Neurosci 30:92-100. CrossRef Medline

Stopfer M, Bhagavan S, Smith BH, Laurent G (1997) Impaired odour discrimination on desynchronization of odour-encoding neural assemblies. Nature 390:70-74. CrossRef Medline

Uchida N, Mainen ZF (2003) Speed and accuracy of olfactory discrimination in the rat. Nat Neurosci 6:1224-1229. CrossRef Medline

Wesson DW, Carey RM, Verhagen JV, Wachowiak M (2008) Rapid encoding and perception of novel odors in the rat. PLoS Biol 6:e82. CrossRef Medline

Youngentob SL, Mozell MM, Sheehe PR, Hornung DE (1987) A quantitative analysis of sniffing strategies in rats performing odor detection tasks. Physiol Behav 41:59-69. CrossRef Medline

Zariwala HA, Kepecs A, Uchida N, Hirokawa J, Mainen ZF (2013) The limits of deliberation in a perceptual decision task. Neuron 78:339-351. CrossRef Medline 